\title{
Assessing the effects of adding Timberland and Farmland into resource-based Sovereign Wealth Fund portfolios
}

\author{
Raul Martinez-Oviedo, Francesca Medda \\ QASER Laboratory, University College London \\ Gower Street, London WC1E 6BT, UK
}

\begin{abstract}
Sovereign Wealth Funds (SWFs) have been prompted to reconsider their traditional asset allocations given the underperformance of equity markets post-2008 financial crisis and the collapse of commodity prices in recent years. Timberland and farmland investments are increasingly attracting the attention of these funds, seeking higher and more stable returns and means to hedge commodity risk. However, analytical analyses on the effect of these investments to SWFs are still limited. This paper studies the effects of including timber and farmland investments in the strategic asset allocation (SAA) of an oil-based SWF. We model the portfolio of investment of an SWF using Norway's Government Pension Fund Global as a case study, and gathering empirical data for the period Q1 2007 - Q1 2016. We examine how allocations in timberland and farmland affect returns, the fund's net growth, and the portfolio exposure to commodity risk. Our results indicate that timber and farmland bring positive effects when supplanting equity investments, improve the return-risk characteristic of the portfolio, and provide hedging again oil risk.

Keywords: Sovereign wealth funds, timber, farmland, asset allocation, oil risk, portfolio optimization.
\end{abstract}

\section{Introduction}

Sovereign Wealth Funds (SWFs) have emerged as a new important class of global investors given the tremendous growth experienced in recent years (Butt et al., 2008; Beck \& Fidora, 2008). An SWF is a government-owned investment vehicle with high foreign asset exposure and long-time horizon that serve 5 multiple financial objectives (i.e. stabilization, saving, preserving investments or pensions) (IWG, 2008). By early 2016, there were over 70 SWFs distributed in more than 40 countries managing assets valued over US 7.1 trillion. According to the SWFI (2016) most SWFs are located in oil-exporting countries funded 
by the revenues realized from the liquidation of commodity assets (e.g. petroleum, gas, and minerals). These revenues are normally invested in highly diversified global portfolios aiming to maximize returns and preserve the wealth of the owning country. The distinctive characteristics of SWFs including their large size, type of ownership, the absence of standard liabilities and low liquidity constraints, provide them with a long-term investment capability no found in other institutional investors such as pension schemes (Stiglitz, 2012).

Despite their long-term capability, SWFs have traditionally focused their strategic asset allocation (SAA) on liquid investment instruments similar to those of other types of funds. The specific SAA adopted by an SWF can, in fact, differ significantly depending on the objectives of the fund (Kunzel et al., 2011). Nevertheless, empirical works reveal most SWF portfolios focus their investments primarily in stocks and bonds, with a strong predominance for the financial sector (Bernstein et al., 2013; Johan et al., 2013; Kotter \& Lel, 2011; Dyck \& Morse, 2011; Chhaochharia \& Laeven, 2008; Jain, 2007). Moreover, Bortolotti et al. $(2013,2009)$ show equity investments have accounted for about $80 \%$ of the total value of investments carried out by SWFs in the past decade. The high preference towards equity can be due to the absence of incentives to commit to other long-term alternatives, as suggested by Spiegel (2012). There are, however, two major factors that are currently influencing the investment strategy of SWFs. First, the growth of equity markets has shrunk considerably after the financial crisis experienced in 2008. As a consequence, equity markets are 25 no longer as attractive as they used to be (Bortolotti et al., 2015). The second major factor is that oil and gas markets have become more competitive with the introduction of the shale oil and gas revolution in the US. The arrival of shale oil and gas have impacted global energy markets, resulting in significantly lower oil prices in recent years, and thus reducing income for SWFs. Encouraged by the situation, these funds are taking a more active role in the direct management of their assets, and new trends are emerging in their SAA as a result (Alhashel, 2015).

The current context seems to be providing incentives for SWFs to seek long-term returns in more illiquid investments instruments. Among illiquid instruments, investments in natural assets such as timber and farmland have called the attention of some of the biggest SWFs, including both commodity and non- 
commodity sourced funds. As an example of this, Xuedong (2014) shows how China Investment Corp. - the 35 worlds third largest SWF has announced their interest in including agricultural assets as part of their new investment strategy. Similarly, Cohen \& McClelland (2015) report that Angola's US $\$ 5$ billion SWF is seeking investments in timber and agriculture to diversify it asset allocations and increase returns. Investments in natural assets are not new to SWFs. The New Zealand Superannuation Fund and Canada's Alberta Heritage Fund are SWFs that have been investing in timber assets since 2005. Other SWFs have followed this trend 40 too. The SovereignWealthFundCenter (2015) reports that 14 different SWFs have executed 51 deals into land, farm, forestry and agricultural businesses over the last 10 years, valued over US $\$ 11.1$ billion. These include the Abu Dhabi Investment Council, Singapore's GIC and Temasek Holdings. The reasons for SWFs to invest in these assets are motivated by the potential of increasing returns, stabilizing volatility, providing portfolio diversification and protection against inflation (TheEconomist, 2014). Yet, only a small portion of 45 SWF portfolios is allocated in natural assets due to liquidity concerns. Timberland and farmland are very illiquid assets compared to bonds or stocks. They take a long time to sell and their returns are driven in many cases by a slow biological growth process. This raises the concern of how to re-balance a portfolio with a significant weight on natural assets, making timberland and farmland unsuitable for many investors with horizons shorter than 10 years. Most institutional investors limit allocations in timberland and farmland to $1-5 \%$ of their portfolio, with only exceptional investors allocating up to $10 \%$ (Binkley et al., 2006). Nevertheless, more recent commercial managers research has started to project that institutional investors may well begin to increase the percentages of portfolio allocation in real assets (which include natural assets) to the range of 15-25\% over the next several years (McNamara, 2015; AquilaCapital, 2014; Azelby, 2012).

When assessing the benefits of investing in natural assets, the inflation hedging property of timber and 55 farmland has been widely recognized in the literature (Wan et al., 2013; Crawford et al., 2013; Mei et al., 2013; Zhang et al., 2011; Healey et al., 2005; Rubens \& Webb, 1995; Courtland \& Binkley, 1993). However, when it comes to assessing other attributes of these assets for institutional investors, such as improving the returnto-risk characteristic or providing diversification, previous works present contradicting findings. On one side, Waggle \& Johnson (2009), Healey et al. (2005) and Kaplan (1985) argue that including natural assets in 
the SAA of institutional investors can yield to positive results by improving the risk-to-return relationship of their portfolio. On the contrary, Scholtens \& Spierdijk (2010) suggest that timberland investments do not significantly improve the mean-variance efficiency of portfolios when removing the appraisal smoothing bias found in natural asset's returns. In view of these considerations, the present work examines the effect of including natural assets in the investment strategy of an SWF. We specifically focus on SWFs funded by oil revenues as they represent the largest fraction of this class of investors. The objective of this analysis is, therefore, to evaluate the performance of an oil-based SWF when including natural assets in its SAA. To address this objective, the authors model the investment portfolio of an SWF over a nine-year period extending from March 2007 to March 2016. We develop our model taking as a case study the portfolio of the world's largest oil funded SWF: The Norwegian Government Pension Fund Global (GPFG). Our findings support the notion that including timber and agricultural investments in the SAA provide high returns, portfolio stability, and resilience against financial downturns. Moreover, we confirm that these assets represent an excellent option for commodity-risk diversification. Based on our results, we argue that SWFs, because of their lower liquidity constraints compared to other investors, can challenge their traditional SAA to increase investments in natural assets. In so doing, these funds can clearly benefit from ${ }_{75}$ these investments.

The content of this paper is structured as follows. In Section 2, we review the literature on SWFs and natural asset investments. In Section 3, we introduce the theoretical framework to model the asset allocation for oil-funded SWFs. In Section 4, we describe the context for the Norwegian GPFG that we use as a case study in our analysis. In Section 5, we present our research methodology including the analytical model developed to assess the performance of an SWF, the data used to construct our investment portfolio, and a description of the analysis conducted to study the impact of adding timberland and farmland into the SAA of an SWF. The results obtained from our work are discussed in Section 6. Finally, in Section 7 we summarize the main findings and propose possible directions in which this work could lead to further investigation. 


\section{Literature review}

The literature on SWFs can be grouped into a number of different streams as shown by Alhashel (2015). A significant part of the works on SWFs focuses on the relationship between the investment decisions of these funds, the global financial landscape and the impact of investments on markets stability. Jensen \& Seele (2013), for instance, investigate the ethical investment guidelines driving decisions in SWF asset allocations and their impact on corporate behaviour. Beck \& Fidora (2008) discuss the wealth transfers of SWFs from developed economies to emerging markets as a result of an asset allocation driven by market capitalization rather than liquidity considerations. Gieve (2009) studies the impact of SWFs on global financial markets and the interaction between global imbalances and the rapid growth of this class of funds. And Balin (2008) evaluates the benefits and critics associated with SWF investments, arguing that these funds can lead to more market liquidity and lower cost of capital. Another group of works focuses on the transparency issue of SWFs. This is the case of Dixon \& Monk (2012) who examine the trade-off between transparency and long-term investing strategy of SWFs. Moreover, Kotter \& Lel (2011) study the investment strategy of SWFs and its association with the transparency policy. The authors find that transparent SWFs are more likely to invest in financially constrained firms compared to opaque SWFs. Caner \& Grennes (2010) argue that the lack of transparency and data limitations in SWFs have made difficult to conduct a systematic analysis of their investment behaviour. The authors also point that the openness of Norway's GPFG has made this particular SWF to be considered as a case study in a large number of analyses.

An important stream of the literature gathers empirical works which examine the SAA of SWFs. Most of these studies indicate that the financial sector has traditionally been, by far, the preferred target of SWFs investments (Johan et al., 2013; Bertoni \& Lugo, 2013; Dyck \& Morse, 2011; Bortolotti et al., 2013, 2009). Boubakri et al. (2016) perform a comparative study between the SAA of SWFs and pension funds, finding that SWFs are more likely to invest in strategic industries such as the financial sector, natural assets, transportation, and telecommunications. Consistent with Johan et al. (2013), findings suggest that SWFs tend also to prefer countries with sustainable economic growth and weak legal and institutional environment. Miceli (2013) identifies a distinctive behaviour of SWFs when allocating assets across industries 
in equity markets compared with another type of investors. Fotak et al. (2008) research the financial impact and wealth effect of SWF investments in global stock markets. And Bernstein et al. (2013) analyse how political involvement influences the investment patterns of SWFs, suggesting that funds with higher political involvement tend to support domestic firms in opposition to funds that relies on external managers.

The stream of the literature probably most related to our work addresses SWFs asset allocation models and risk-return analysis. Scherer (2011) shows how to model the optimal asset allocation for an oil-based SWF as a function of the oil extraction policy of the owning country. The author finds that SWFs decisionmaking problems can be modelled as an optimal asset allocation with endowed and non-tradable wealth. Moreover, Gintschel \& Scherer (2008) develop an optimization model for oil-sourced SWF portfolios considering the oil endowment of the owning country as an inherited risk the SWF portfolio wants to diversify; this work provides the theoretical framework to analyse investment decisions of commodity based SWFs. Following this framework, Bertoni \& Lugo (2013) build a mean-variance model to statistically test the actual SAA of the GPFG to a theoretical optimum. Their empirical analysis demonstrates that the deviations shown by the GPFG's portfolio are consistent with theoretical predictions, meaning that the SAA of the GPFG takes into account the diversification of the risk linked to Norway's oil reserves. Papaioannou \& Rentsendorj (2015) also analyse the SAA of the Norwegian fund using Markowitz portfolio theory. Their analysis suggests that the GPFG's SAA is broadly consistent with the allocations generated by the oneperiod Markowitz model. Finally, vandenBremer et al. (2016) introduce a new framework to coordinate the management of below- and above-ground sovereign wealth by integrating portfolio allocation theory with precautionary saving and optimal oil extraction under oil price volatility. The authors, in addition, provide suggestions to improve the GPFG management. Regarding the return-to-risk analysis, one of the most prominent works evaluating the GPFG is presented by Ang et al. (2009). In their work, authors show that the optimal SAA is the most significant source of total returns for Norway's fund.

In relation to natural asset investments (i.e. timberland and farmland), several works in the literature have dedicated to studying their effect when included into the investment portfolio of institutional investors. Findings seem nonetheless to be contradicting, suggesting in some cases positive effects and in other cases 
failing to find evidence of significant improvement. Kaplan (1985) describes the return characteristic of farmland investments and assesses their diversification potential when included as an asset in an investment portfolio. Using Markowitz optimization, the author concludes that farmland investments contribute to improving the efficient frontier of portfolios by providing a higher return-to-risk characteristic. In line with these findings, Lins et al. (2016) found that adding farmland to a portfolio of stocks, corporate bonds, and real estate results in higher risk-adjusted returns. Rubens \& Webb (1995) show farmland to be a good inflation hedge and to provide low positive to negative correlation with equities. However, more recent works including Hardin \& Cheng (2002) and Hardin \& Cheng (2005) suggest that there is no evidence of any significant benefits from including farmland to a portfolio of real estate while using alternative risk assumptions. As for timber assets, a number of studies report improvement in the return-risk characteristic of a portfolio when timber is included. Healey et al. (2005) argue that the unique attributes of timber investments (i.e. higher expected returns, low associated risk, timber's economy, and inflation hedging) allow a portfolio with a timberland component of 10 percent to yield highly positive results. Zhang et al. (2011) and Waggle \& Johnson (2009) also find significant benefits when timberland is added into a portfolio of stocks, bonds, and T-bills. On the contrary, the analysis presented by Scholtens \& Spierdijk (2010) concludes that, after removing the appraisal smoothing bias from timberland returns, there is no evidence that adding timber into a portfolio mix of traditional assets can increase mean-variance efficiency.

This article contributes to the latest above-mentioned stream of the SWF literature and with the literature on natural assets investments. By modelling the investment portfolio of an oil-sourced SWF, based on the theoretical framework developed by Gintschel \& Scherer (2008) and the methodological approach introduced by Bertoni \& Lugo (2013), we test the long-run performance of an SWF portfolio when timber and farmland are included in the SAA. Our findings show that natural asset investments can yield to higher return-risk ratio, diversify commodity risk of price fluctuation, and reduce capital losses, suggesting that these assets can be considered as a serious alternative in the long-time strategy of SWFs. To the best of our knowledge, no analysis in the existing literature examines the effect in the long-term performance of adding natural assets into the SAA of an oil-based SWF. 


\section{Theoretical framework}

The theoretical framework developed by Gintschel \& Scherer (2008) addresses the optimal asset allocation problem for oil-sourced SWFs. This framework differentiates a country's wealth into two main components: a fraction, $\omega$, that represents the value of subsoil assets (e.g. oil reserves); and a remaining fraction, $(1-\omega)$, that represents the value of above-ground assets in the form of an SWF that is invested in financial securities. Oil resources are determined by the size of oil reserves $x_{o}$, in million barrels, and the price per barrel $p_{o}$. The total value of oil resources is therefore, $x_{o} p_{o}$, and changes in oil prices determine their expected return $r_{o}$, and risk $\sigma_{o}$ that the country wants to diversify. The value of above-ground assets is given by the market value of the fund $v_{f}$, which is invested in a portfolio of N-risky securities with weights $\mathbf{w}$, such that $\mathbf{1}^{\mathrm{T}}$ $\mathbf{w}=1$. The return of the N-risky assets over the period of analysis is given by the vector $\mathbf{z}$, and their covariances are provided by the matrix $\boldsymbol{\Sigma}$. The return on the portfolio is $r_{p}$. Therefore, the change in total wealth (i.e. oil reserves and financial assets) is given by $r=\omega r_{o}+(1-\omega) r_{p}$, where $\omega=x_{o} p_{o} /\left(x_{o} p_{o}+v_{f}\right)$ is the value of oil reserves relative to aggregated wealth. The exposure of financial assets to oil risk is captured by the oil sensitivity of the asset's returns collected in a vector $\mathbf{b}$, whose elements $b_{i}=\operatorname{Cov}\left(z_{i}, r_{o}\right) / \sigma_{o}$. In consequence, the oil exposure of a financial portfolio $\mathbf{w}$, is defined as $\mathbf{w}^{\mathrm{T}} \mathbf{b}$.

Following the standard definition, an optimal asset allocation is defined by a portfolio that minimises variance for a given expected return. Gintschel \& Scherer (2008) distinguish between two possible choices for the optimal portfolio: a locally efficient portfolio and a globally efficient portfolio. A locally efficient portfolio neglects the commodity risk of a country. In the standard mean-variance framework, as commonly applied in practice, the locally efficient portfolio is obtained by solving the problem

$$
\mathbf{w}^{*}=\underset{\mathbf{w}}{\operatorname{argmin}} \mathbf{w}^{\mathrm{T}} \boldsymbol{\Sigma} \mathbf{w}
$$

subject to achieving a target expected return $\mu$, such that $\mathbf{z}^{\mathrm{T}} \mathbf{w}=\mu$, and to the constrains $\mathbf{1}^{\mathrm{T}} \mathbf{w}=1$. The solution to this problem is denoted by $\mathbf{w}_{L}(\mu)$ which is efficient in isolation.

A global efficient portfolio $\mathbf{w}_{G}(\mu)$, on the contrary, takes into consideration the commodity risk and it yields to an efficient combined portfolio that minimizes the variance of changes in aggregate wealth, given 
by

$$
\operatorname{Var}(r)=\omega^{2} \sigma_{o}^{2}+(1-\omega)^{2} \mathbf{w}^{\mathrm{T}} \boldsymbol{\Sigma} \mathbf{w}+2 \omega(1-\omega) \sigma_{o}^{2} \mathbf{w}^{\mathrm{T}} \mathbf{b}
$$

subject to the constraints $\mathbf{1}^{\mathrm{T}} \mathbf{w}=1$ and $\mathbf{z}^{\mathrm{T}} \mathbf{w}=\mu$. It is worth noticing that the solution of the global portfolio has the same expected return $\mu$ as the locally efficient portfolio, independently of the expected oil price change. This avoids the need of making further assumptions on the expected oil price change. It can be proven (see Gintschel \& Scherer (2008) and Bertoni \& Lugo (2013)) that for any desired return $\mu$, the globally efficient portfolio can be expressed as a linear combination of the locally efficient portfolio and a hedge portfolio $\mathbf{w}_{H}$ as follows

$$
\mathbf{w}_{G}=\mathbf{w}_{L}(\mu)+\frac{\omega}{(1-\omega)} \mathbf{w}_{H}
$$

where

$\mathbf{w}_{H}=\sigma_{o}^{2}\left\{-\boldsymbol{\Sigma}^{-1} \mathbf{b}+\boldsymbol{\Sigma}^{-1} \mathbf{z} \frac{1}{\Delta}\left[\left(\mathbf{1}^{\mathrm{T}} \boldsymbol{\Sigma}^{-1} \mathbf{1}\right)\left(\mathbf{z}^{\mathrm{T}} \boldsymbol{\Sigma}^{-1} \mathbf{b}\right)-\left(\mathbf{z}^{\mathrm{T}} \boldsymbol{\Sigma}^{-1} \mathbf{1}\right)\left(\mathbf{1}^{\mathrm{T}} \boldsymbol{\Sigma}^{-1} \mathbf{b}\right)\right]+\boldsymbol{\Sigma}^{-1} \mathbf{1} \frac{1}{\Delta}\left[\left(\mathbf{1}^{\mathrm{T}} \boldsymbol{\Sigma}^{-1} \mathbf{b}\right)\left(\mathbf{z}^{\mathrm{T}} \boldsymbol{\Sigma}^{-1} \mathbf{z}\right)\right]\right\}$

is a zero- net investment, zero-expected return hedge portfolio, and $\Delta=\left(\mathbf{z}^{\mathrm{T}} \boldsymbol{\Sigma}^{-1} \mathbf{z}\right)\left(\mathbf{1}^{\mathrm{T}} \boldsymbol{\Sigma}^{-1} \mathbf{1}\right)-\left(\mathbf{1}^{\mathrm{T}} \boldsymbol{\Sigma}^{-1} \mathbf{z}\right)\left(\mathbf{z}^{\mathrm{T}} \boldsymbol{\Sigma}^{-1} \mathbf{1}\right)$.

Thus, for any target return the globally efficient portfolio can be derived from a locally efficient portfolio using the hedge portfolio $\mathbf{w}_{H}$.

Excluding some special cases, such as when commodity is riskless (i.e. $\sigma_{o}=0$ ), when its risk is orthogonal to the risk of financial assets (i.e. $\mathbf{b}=0$ ) or when the country does not want to diversify its commodity ${ }_{185}$ risk (i.e. $\omega=0$ ), it is found that the locally efficient and the globally efficient portfolios are different. In general, for a given level of return, $\mathbf{w}_{G}(\mu)$ will have a higher stand-alone risk and a lower Sharpe ratio than $\mathbf{w}_{L}(\mu)$. An oil-funded SWF aiming to diversify oil risk will not invest in the locally efficient portfolio, but rather, it will invest in the globally efficient portfolio that takes into account the sensitivity of financial assets with oil $\mathbf{b}$. Assets exhibiting high sensitivity with oil risk tend to be underweighted, and the sensitivity to commodity risk can be more tolerated in assets with higher expected returns. Therefore, when analysing the performance of an SWF, it should be done considering the globally efficient portfolio, otherwise results would provide consistently incorrect conclusions (Bertoni \& Lugo, 2013). 


\section{Case study: Norway's Government Pension Fund Global}

Norway is one of the most developed economies in the world. Much of Norway's economic growth has been supported by its abundance of natural resources, including exports of fishery, hydro-power, and most significantly, petroleum products. As for 2015, Norway was ranked the 8th-largest oil exporter in the world, and the 3th-largest natural gas exporter (NPD, 2015). Oil reserves in this country are estimated at 6.5 billion barrels, which roughly translate into a market value of US $\$ 325$ billion (considering a $\$ 50$ oil barrel). Part of the revenues derived from oil activities is channelled into Norway's SWF: The Government Pension Fund Global (GPFG). The GPFG is currently the world's largest SWF, managing assets valued in over US\$820bn (SWFI, 2016). Thus, the ratio of oil reserves to aggregated wealth for the Norwegian fund approximates to $\omega=0.28$. The fund was formally set up in 1990 as a petroleum fund to manage Norway's natural wealth in the long-term and to contribute to Norway's strategy for sustainable development (MinistryOfFinance, 2008). The idea behind establishing the fund was to channel revenues from oil activities into a diversified portfolio of international securities. Since its inception, the GPFG has received about 3,499 billion kroner (approx. US $\$ 423.6 \mathrm{bn}$ at present exchange rate) from oil revenues. Table 1 shows the oil production trajectory, together with oil revenues and capital transfer to the fund, experienced by Norway in the past decade. Oil production in Norway has been declining at an average rate of $5 \%$ per year since 2005 , going from nearly annual 932 MMbarrel to 572 MMbarrel. Revenues perceived from oil are the result of different petroleumrelated activities, including taxes, environmental taxes, royalties, government direct participation in the oil business, and dividends from the national oil company Statoil. Total revenues have been fluctuating between US\$1,400bn and US $\$ 2,700 \mathrm{bn}$ per annum, decreasing in the last three years as a result of falling oil prices. The portion of total revenues annually transferred to the fund is estimated to oscillate in the range of $47-87 \%$ per year, averaging $67.7 \%$ over the past ten years.

\section{[ Insert Table 1 about here ]}

The GPFG portfolio model focuses on public traded securities depending mainly on beta returns rather than alpha returns, in contrast with the Swensen model (Chambers et al., 2012). Regarding the most 
distinctive characteristics, Dimson et al. (2010) and the MinistryOfFinance (2015) highlight the fund's large size, its long-term investment horizon, the absence of specific liabilities, its ownership and governance structure, and its high level of transparency. These characteristics provide the fund with a greater than average risk tolerance that, in combination with an effective SAA, have allowed the GPFG to excel in performance achieving rates of return higher than those of many other equity investors (Caner \& Grennes, 2010). The fund's market size has grown approximately 173\% over the period Q1 2007 - Q1 2016, reporting an average quarterly return of $1.3 \%$ with a volatility of $5.15 \%$, and an oil sensitivity of 0.11 . The SAA of the GPFG is defined by the mandates introduced by NorgesBank (2016). Table 2 summarizes the mandates for the Norwegian fund adopted in early 2016. The strategy adopted by the GPFG defines a portfolio invested in three main instruments: equities $(61 \%)$, fixed-income (36\%), and real estate (3\%). The equity portfolio is invested in companies listed in recognized marketplaces in Europe (excluding Norway), North America, Asia and Emerging Markets. Top listed companies include Nestle SA, Apple Inc., Roche Holdings AG, Novartis AG, Alphabet Inc., Microsoft Corp., BalckRock Inc., HSBC Holdings Plc, Royal Dutch Shell Plc, Prudential Plc, and Exxon Mobil Corp. The fixed-income portfolio is invested in tradable government and corporate bonds and debt instruments. Due to liquidity risk limits, the mandates dictate that a minimum of $10 \%$ of the portfolio shall be held in liquid instruments, defined as treasury bonds issued by the governments of the US, UK, Germany, France, or Japan. Finally, the real estate portfolio is invested according to a policy of geographic diversification including markets in the US, UK, Europe, and Asia. These investments include rights acquisition of office, retail, logistic, and dwelling buildings, but exclude investments in infrastructure projects. The mandates also introduce limits for the management costs as a percentage of assets under management. Limits to the cost are approved in advanced based on estimations for the following year and historically they have not exceeded $0.1 \%$ of total assets under management in the last ten years. 


\section{Research methodology}

\subsection{Analytical model}

To address the objective of this paper, we model the portfolio of investment of an SWF based on Norway's model and test its performance when including natural asset investments into its SAA. The analysis extends over a 9-year time span starting from Q1 2007 and ending in Q1 2016, discretised on a quarterly basis (37 quarters). For the purpose of this analysis, we are assuming an oil-funded SWF that wants to diversify its commodity risk. The fund is set up with an initial market value at the beginning of the period that changes over time depending on return on investments, management expenses, and fluctuations in oil revenues. We also assume that the fund follows a global investment strategy with allocations in equity, real estate, and fixed-income instruments. These investments are geographically diversified across North America, Europe, Asia, and Latin America. Equity investments include stock acquisition in listed companies from eight different sectors, namely: consumer goods, consumer services, energy, finance, healthcare, industrial, technology, and utilities. Investments in real estate include property markets in the US, UK, Europe, and Asia. Fixed-income investments have been limited to the US bond market. In addition to these traditional assets, investments in timber and farmland assets are included into the portfolio. Investments in timber refer to the acquisition of trees and forestland, including the operations of growing, harvesting, processing and distributing timber products. Farmland investments encompass the purchase and management of agricultural operations, including crops and livestock.

The performance of the fund over time is assessed by measuring the variations of its size, average quarterly returns, volatility, inflows from oil activities, and portfolio exposure to oil risk. The market value of the fund at time $t, v_{t}$, depends on the size at a previous time instant, and the current difference between inflows and outflows perceived by the fund, expressed as

$$
v_{t}=v_{t-1}+\left(I_{t}-C_{t}\right), \quad \forall t \in[1, T]
$$

where the term $\left(I_{t}-C_{t}\right)$ represents the difference between inflows and outflows experienced at time $t$. The outflows of the fund are primarily given by the management cost, $C_{t}$, assumed to be a fraction of the total 
value of assets under management, given by

$$
C_{t}=\phi M_{t-1}
$$

where $0<\phi<1$. The inflow of the fund, $I_{t}$, is given by two components: the revenues derived from oil income allocated to the fund, and the returns derived from the global investment portfolio. Oil revenues depend on both export levels, $e_{t}$, and oil prices, $p_{t}$, written as

$$
r_{t}=\gamma e_{t} p_{t}
$$

where $\gamma$ is the fraction of oil revenues allocated to the fund.

The returns on global investments are given by the composite returns obtained for the asset classes equity, $r_{t}^{e q}$; real estate, $r_{t}^{r e}$; fixed-income, $r_{t}^{f i}$; and natural assets $r_{t}^{n a}$. If we have $N^{e q}, N^{r e}, N^{f i}$, and $N^{n a}$ risky investment alternatives for equity, real estate, fixed-income, and natural assets, respectively, the composite returns for each asset class is computed as

$$
\begin{aligned}
& r_{t}^{e q}=\mathbf{z}_{t}^{e q \mathrm{~T}} \mathbf{w}_{t}^{e q} \\
& r_{t}^{r e}=\mathbf{z}_{t}^{r e \mathrm{~T}} \mathbf{w}_{t}^{r e} \\
& r_{t}^{f i}=\mathbf{z}_{t}^{f i \mathrm{~T}} \mathbf{w}_{t}^{f i} \\
& r_{t}^{n a}=\mathbf{z}_{t}^{n a \mathrm{~T}} \mathbf{w}_{t}^{n a}
\end{aligned}
$$

where $\mathbf{z}_{t}^{e q}, \mathbf{z}_{t}^{r e}, \mathbf{z}_{t}^{f i}$ and $\mathbf{z}_{t}^{n a}$ are the vectors containing the individual returns for each equity, real estate, fixed-income, and natural asset, respectively. And $\mathbf{w}_{t}^{e q}, \mathbf{w}_{t}^{r e}, \mathbf{w}_{t}^{f i}$ and $\mathbf{w}_{t}^{n a}$ denote the weights for the equity, real estate, fixed-income, and natural assets portfolio, respectively.

Global efficient portfolios, $\mathbf{w}_{G, t}^{e q}, \mathbf{w}_{G, t}^{r e}, \mathbf{w}_{G, t}^{f i}$ and $\mathbf{w}_{G, t}^{n a}$ for each asset class are estimated every quarter taking into account the commodity risk. Following Bertoni \& Lugo (2013), we compute the global efficient 
portfolios using Monte Carlo resampling technique, as described by Michaud (1998). Resampling techniques provide a stronger reduction in the under diversification of the estimated portfolio, particularly when constraints are added to weights (Scherer, 2002). In order to avoid null weights, we impose constraints to the minimum and maximum weights assigned to particular assets. In the case of equities, we apply a minimum of $0.5 \%$ and a maximum of $11 \%$ for each sub-asset. For real estate, the minimum and maximum weights are $0.5 \%$ and $25 \%$, respectively. And for natural assets, a minimum of $10 \%$ and a maximum of $90 \%$ is imposed. When using resampling, 500 Monte Carlo simulations were run to generate 300 portfolios. In each simulation, the covariance matrix and the oil sensitivity vector $\mathbf{b}$ are estimated using part of the historical quarter returns for scenario generation, and the rest of the historical data for evaluating the performance of the investment strategy. This technique is referred to as out-of-sample analysis. The optimal portfolio derived from resampling is chosen as the one that maximizes the Sharpe ratio, using US Treasury Bills as the risk-free asset.

By combining Equation (7) and Equations (8)-(11), the inflows of the fund can be expressed as follows

$$
I_{t}=\gamma e_{t} p_{t}+v_{t-1}\left(\alpha^{e q} r_{t}^{e q}+\alpha^{r e} r_{t}^{r e}+\alpha^{f i} r_{t}^{f i}+\alpha^{n a} r_{t}^{n a}\right)
$$

where the variables $\alpha^{e q}, \alpha^{r e}, \alpha^{f i}$, and $\alpha^{n a}$ are introduced to represent the allocation mandate policy established by the fund to invest in equity, real estate, fixed-income, and natural assets, respectively. Substituting Equations (6) and (12) into Equation (5) and reorganizing, allow us to rewrite the fund market value as

$$
v_{t}=\gamma e_{t} p_{t}+v_{t-1}\left[1+\left(\alpha^{e q} r_{t}^{e q}+\alpha^{r e} r_{t}^{r e}+\alpha^{f i} r_{t}^{f i}+\alpha^{n a} r_{t}^{n a}\right)\right]-\phi v_{t-1}
$$

This equation is used to model and evaluate the growth trajectory of the fund when inputting the data described in the following section.

\subsection{Data and portfolio construction}

Following the SAA of the GPFG, the construction of the portfolio considers an investment universe composed of 25 equity markets, 4 real estate markets, and 1 bond market. These investments are assumed to be geographically distributed across North America, Europe, Asia, and Latin America. Table 3 shows 
the detailed investment universe considered in our analysis. The data required to model the investment universe has been obtained from Thomson Reuters and Bloomberg databases, and it consists of historical time series of quarterly returns over a nine-year period (Q1 2007-Q1 2016). Additional 28 observations (Q1 2000-Q4 2006) have been taken to perform the out-of-sample analysis for the first point in the modelled period. Equity investments include stock acquisitions in the sectors of consumer goods, consumer services, energy, finance, healthcare, industrial, technology, and utilities. These investments are proxied using indices from US Dow Jones, Stoxx Euro 600, Thompson Reuters, and MSCI. Investments in real estate include the property markets in the US, UK, Europe, and Asia and South Pacific and their returns are represented by Thompson Reuters property indices from their respective regions. As for fixed income, investments are limited to the US bond market represented in the Barclay's Capital US Aggregated Bond Index.

\section{[Introduce Table 3 about here]}

In addition, based on the mandates adopted by the Norwegian fund, we assume that $60 \%$ of total assets is Trusts in the US, respectively. Income returns arise from sales of timber and farm products according to production, whereas appreciation returns results from timber, farm and land appreciation. NCREIF indexes 
are computed based on the appraisal of recent property transactions; therefore, the indexes suffer from appraisal smoothing bias that makes the volatility of the observed returns too low in comparison to the true unobserved returns (Scholtens \& Spierdijk, 2010). To avoid an over-optimistic picture of the diversification potential of the NCREIF indexes, we consider unsmoothed index returns using the unsmoothing approach introduced by Fisher et al. (1994) (see Appendix A). In doing so, the volatility condition adopted is based on the assumptions that the volatility of commercial timber and farm properties is approximately $1 / 2$ the volatility of the S\&P500 Index.

\subsection{Portfolio analysis}

The performance analysis is done by developing a simulation model in Matlab of the investment portfolio of an SWF funded by the revenues derived from oil activities. The revenues from oil activities are modelled using historical trajectories of oil production in Norway (Table 1) as reported by the Norwegian Petroleum Directorate (NPD, 2015), and historical time series of quarterly oil prices using the Brent Spot FOB as a reference. The oil inflows to the fund are assumed to be given by a constant fraction of $70 \%$ of total oil revenues. This fraction is introduced based on the average relationship between the oil inflows reported by the GPFG and the total oil revenues from oil activities reported by the Norwegian government between 2007 and 2014. The test case fund is set up with an initial market value of $\$ 305.4 \mathrm{bn}$ at the beginning of the evaluation period. This number is in line with the market value of the GPFG reported during the first quarter of 2007. Total management cost per quarter has been considered to be $0.02 \%$ of the total value of assets under management. This consideration is based on the average quarterly costs reported by the Norwegian fund between 2004 and 2015.

In order to evaluate the effects of including timber and farmland investments in the SWF allocation strategy, 16 different portfolios are analysed. Table 4 provides a description of the different portfolios compared in our analysis. The different portfolios include the baseline portfolio (portfolio 1) and the portfolios resulting from displacing investments from traditional assets into natural assets at three different levels: $15 \%, 20 \%$, and $25 \%$. Therefore, we find the cases when supplanting equity investments (portfolios 2-4), fixed-income investments (portfolios 5-7) and real estate investments (portfolios 8-10) by investments in 
natural assets. These portfolios have been chosen to compare the effects that natural assets replacement has when applied to the different traditional asset classes. In addition, we consider the portfolios resulting from reducing equity investments at the expenses of increasing investments in fixed-income (portfolio 11-13) and real estate (portfolios 14-16) while excluding allocations in natural assets. These portfolios are considered with the purpose of comparing the effects of displacing equity investments into another traditional asset class rather than into natural assets. Each of the tested portfolios is ranked based on their performance when considering net growth, average returns, overall risk (i.e. considering oil and financial assets), maximum draw down, and the portfolio exposure to oil sensitivity. Additionally, we examine the effects that oil risk has over the oil inflows to the fund and its contribution to market value growth.

\section{[ Insert Table 4 about here ]}

\section{Results}

\subsection{Analysis of asset returns}

We begin our analysis by comparing the performance of historical returns of the different assets considered in our investment universe. Table 5 shows the descriptive statistics of the assets quarterly returns based on their historical performance during the period Q1 2007- Q1 2016. From the table, it can be observed that different assets exhibit significant different performance. North American equities and real estate registered a better performance compared with their similar markets in Europe and Asia, exhibiting generally higher average returns and lower volatilities. The best performances within equities, when considering the Sharpe ratio, were found for North American consumer goods (0.209), consumer services (0.226), healthcare (0.250), and technology $(0.166)$. These relatively high ratios may promise preference toward these assets when allocating weights within equities. Other equity markets exhibiting a moderate performance includes European consumer goods (0.129) and healthcare (0.182), and Asian consumer goods (0.012). Real estate markets, excluding the North American market, did not perform well during the examined period showing negative average returns and high levels of volatility. Particularly, the UK real estate (-0.086) and European real estate (-0.030) markets presented some of the lowest Sharpe ratios, together with the Asian property 
market (-0.028). On the contrary, the US bond market exhibits one of the best performances among the assets in our universe, registering an average quarterly return of $1.14 \%$, a volatility of $1.60 \%$, and a Sharpe ratio of 0.603. Unsmoothed timber and farmland are among the assets with higher returns and lower volatility too, comparable with the best performing equities and the US bond market. The average quarterly return for unsmoothed timberland and farmland during the considered period were $1.40 \%$ and $2.79 \%$, respectively, with a standard deviation of $3.73 \%$ and $3.20 \%$ in each case. The Sharpe ratios of timber (0.329) and farmland (0.816) confirm their good performance, ranking within the top three performing assets together with the US bond market.

\section{[ Insert Table 5 about here ]}

When examining the relationship of assets with oil risk (Table 5), we find that the oil sensitivity for North American bonds (-0.020), timberland (0.010), and farmland (0.004) are very low or even negative compared with the rest of the assets. Thus, placing allocations among these assets may provide advantages in hedging oil price risk. We can expect higher weights to be allocated, in particular, to those assets with lower oil sensitivity and higher expected return. Other assets exhibiting low oil sensitivity includes North American real estate (0.061), North American utilities (0.083), Europe consumer services (0.031), and Asian healthcare (0.058) and utilities (0.007). Some of these assets, however, also present significantly low or even negative expected returns. Therefore, they are unlikely to have an impact on the asset allocation. North American consumer goods (0.110), consumer services (0.138) and healthcare (0.126), European consumer goods (0.194), healthcare (0.148) and utilities (0.240), and Asian consumer services (0.119) and technology (0.256) are among the assets exhibiting a moderate oil sensitivity. While energy, financial, and industrial sectors in all the geographical zones, together with the Latin American equity market, show significantly higher levels of oil sensitivity. Moderate and high levels of oil sensitivity may be tolerated depending on whether assets promise high levels of return or not. From the initial examination of the historical performance of the data, we can expect that portfolios with a significant component of those assets with low oil sensitivity and high Sharpe ratio, could in principle lead to better performance of the overall portfolio. 
Figure 1 shows the performance of the modeled SWF when using the SAA defined by the baseline portfolio (portfolio 1, excluding natural assets) during the evaluated period. The figure also compares this with the actual performance registered by the GPFG during the same period. From the figure, it can be observed that our baseline portfolio mirrors the behaviour of the GPFG. The correlation between the returns of the baseline portfolio and the GPFG is 0.951 , and the correlation between their market value trajectories is 0.996. This represents a fairly good approximation of the Norwegian fund for the purpose of our analysis. A more precise replication of its behaviour would require more detailed data of the GPFG's allocation strategy. The market value of the modelled fund when using the baseline portfolio was steadily increasing until the last quarter of 2007. As a consequence of the financial crisis, significant negative returns were experienced during the period Q4 2007-Q3 2008, resulting in a fall of the fund value due to the downturn of global markets. From the summer of 2009, the fund started to recover again continuously growing until the first quarter of 2014 when the market value stabilized due to the fall of oil prices. Using the baseline portfolio, the SWF experienced a net growth of $191.5 \%$ on its market value, going from its initial US\$ 305.4 bn in Q1 2007 to US\$ 890.2 bn in Q1 2016. Total returns of the portfolio averaged $0.67 \%$ per quarter (2.7\% a year) with a volatility of total wealth (oil and financial assets) of $9.2 \%$. The average return to overall risk ratio achieved is 0.072 and the oil exposure of the overall portfolio is 0.138 , with a high positive correlation with oil prices of $55.5 \%$. When introducing changes in the SAA of the baseline portfolio, significant variations in the performance of the SWF were found. Table 6 summarizes the results obtained for the sixteen different portfolios tested. The table ranks the portfolios according to their performance as reflected by the return to overall risk ratio, where the overall risk is defined in Equation (2) to consider the aggregated wealth. A careful examination of the figures in the table allows to extract some interesting observations:

\section{[ Insert Figure 1 about here ]}

\section{[ Insert Table 6 about here ]}

First, out of the sixteen portfolios analysed, the baseline portfolio is ranked 13 (shown in bold in the 
table) suggesting that most changes of transferring equity investments into another asset type actually benefit the SWF performance. This observation is particularly true when equity investments are replaced by investments in natural assets (portfolios 2, 3, 4) or fixed-income instruments (portfolios 11, 12, 13). However, the observation does not hold true when the replacement is done in real estate. Reducing equity investments to increase allocations in real estate was found to be counterproductive as the resulting portfolios (portfolios 14, 15, 16) underperformed the baseline portfolio. Second, the best performance results from replacing equity investments with natural asset investments (portfolios 2, 3 and 4) rather than fixed-income or real estate. Increasing allocations in natural assets at the expenses of reducing equity investments, contribute to significantly improve all the performance indicators. Moreover, it is found that the higher the percentage displaced from equities into natural assets, the better the performance. For instance, when $15 \%$ of the Equity allocation is shifted to natural assets (portfolio 2), the return-to-overall risk ratio of the portfolio improved from 0.072 to 0.096 . The maximum drawdown was diminished from $39.2 \%$ to $32.7 \%$, allowing a faster recovery of the market value to the pre-crisis level. And the net growth in market valued was enhanced from $191.5 \%$ to $207.5 \%$. The oil exposure of the overall portfolio is also decreased from 0.1379 to 0.1180 . These improvements in the indicators are even higher when shifting $25 \%$ of equity allocations into natural assets (portfolio 4). In this case, the return-to-risk ratio is improved to 0.114, the maximum drawdown is reduced to $28.3 \%$, the net growth is enlarged to $218.4 \%$, and the oil exposure is reduced to 0.1047, registering the best performance among all the portfolios compared. The second best effects are observed when moving equity investments into fixed-income (portfolios 11, 12 and 13). Although all the indicators show significant improvements compared with the baseline portfolio too, the level of improvement is not as high as the one achieved with natural assets. Finally, portfolios including natural asset investments, in general, perform better compared with those without natural assets. No portfolio containing allocations in natural assets underperform the baseline. Among those portfolios with natural assets component, those ones in which natural assets replace real estate (portfolios $8,9,10$ ) rank the lowest. This is due to the low fraction allocated to these assets. 
natural assets (portfolio 4), fixed income (portfolio 13) and real estate (portfolio 16) respectively, together with the baseline portfolio. Figure 2 shows the quarterly returns and market value trajectories for these portfolios. The figure illustrates how portfolio $4(\mathrm{Eq}=45 \%, \mathrm{Fi}=35 \%, \mathrm{Re}=5 \%, \mathrm{Na}=15 \%)$ exhibits the best performance, achieving an average return $0.29 \%$ higher, an overall volatility $0.76 \%$ lower, and a growth $27 \%$ greater compared to the baseline. Portfolio $13(\mathrm{Eq}=45 \%, \mathrm{Fi}=50 \%, \mathrm{Re}=5 \%, \mathrm{Na}=0 \%)$ also improves the performance relative to the baseline portfolio providing an average return $0.1 \%$ higher, an overall volatility $0.82 \%$ lower and a net growth $9.5 \%$ larger. Yet the improvement provided by this portfolio is still lower compared to portfolio 4. As for portfolio $16(\mathrm{Eq}=45 \%, \mathrm{Fi}=35 \%, \mathrm{Re}=20 \%, \mathrm{Na}=0 \%)$, its effects on the performance were rather negative. Despite the overall risk decreased $0.14 \%$, the average return also decreased $0.08 \%$, providing a return-to-risk ratio 0.008 lower and shrinking growth in $0.1 \%$ in comparison to the baseline.

\section{[ Insert Figure 2 about here ]}

In Figure 3, we present the global efficient allocations for portfolio 4 across the evaluation period. Efficient allocations in equity are well diversified among the different sectors. Some of the sectors that receive the greatest weights steadily throughout the period include North America consumer good, European consumer goods and healthcare, and Asian energy and utilities. That is, in general, sectors with lower oil sensitivity and higher expected returns. Sectors with a relatively low expected return and high volatility, such as European and Asian consumer services, or sectors with a high oil sensitivity compared to their Sharpe ratio such as finance, industrial and technology in the three continents, receive low weights during the whole period. Other sectors with a variable performance, such as North American healthcare and utilities, and Asian healthcare, received low weight during the quarters close to the crisis that progressively increased in the quarters after the crisis. A contrary behaviour is observed for Latin American equity, which receives significant weights during the crisis quarters that diminish in the most recent quarters. As for real estate markets, the highest weights are given to the North American, European and Asian markets, while the UK receives the lowest weight staying almost invariant during the examined period. The weights given to the fixed income instrument remain constant (35\%) as only one asset is considered in this category. Regarding 
the natural asset components, we find that farmland is noticeably favoured receiving the largest proportion of the allocation along the period, while timberland receives the smallest one. Farmland returns are associated with a higher expected return and lower oil sensitivity when compared with timberland.

\section{[ Insert Figure 3 about here ]}

\subsection{Oil exposure analysis}

Oil inflows to the fund are a direct expression of the oil risk. Figure 4 shows the oil inflows perceived by our modelled SWF during the studied period. Inflows to the fund were steadily increasing until the second quarter of 2008, driven by the rapid rise of oil prices experienced in the quarters before the crisis. By the down to an average of $2.5 \%$ per quarter until Q2 2014. The growth rate was slowed further after the second half of 2014, as a result of the collapse of oil prices, averaging only 0.8\% per quarter from Q3 2014 to Q1 2016. The speed at which the cumulative value of oil inflows increases is affected by the oil risk. Higher prices of oil would in principle lead to a rapid increase, while lower prices would slow it down.

\section{[ Insert Figure 4 about here ]}

[ Insert Figure 5 about here ] 
The hedging capability of the investment portfolio against the oil risk, together with its expected return, contributes to the speed at which the portfolio grows. A portfolio presenting better hedging properties is able to offset oil risk, and therefore, reduce losses from oil prices fall. The analysis of the oil exposure for the tested portfolios reveals that a portfolio with natural assets can provide significant hedging against oil risk compared to the baseline. Figure 6 presents the oil exposure registered for portfolios 1, 4, 13, and 16 across the evaluation period. For the different portfolios examined, the SWF registered a negative exposure to the commodity risk until the third quarter of 2008. When oil prices were rising and global financial markets were performing well, the allocation strategies defined by the global portfolios allow the allocations to exhibit the negative oil sensitivity necessary to output a negative exposure. The baseline portfolio in this case presented the least negative exposures, registering an average of -0.0060 between Q2 2007 and Q3 2008. A portfolio in which $25 \%$ of equities allocations are replaced by natural assets (portfolio 4) exhibits a more negative exposure during the same period with an average of -0.0161. An even greater improvement is obtained for the cases in which the $25 \%$ of equity investments are shifted to fixed income (portfolio 13) or real estate (portfolio 16) averaging -0.0221 and -0.0275 , respectively. After the final quarter of 2008, oil prices failed together with most equity markets. As a result, a positive exposure is exhibited for the portfolios during the remaining quarters. In this case, the baseline portfolio presents the highest exposure to oil risk, averaging 0.1159 during the period Q4 2008-Q1 2016. Portfolio 4, which include natural assets, significantly reduces the oil exposure compared to the baseline. The average exposure for this portfolio was reduced to 0.0855 for the same period. It is worth noticing here, that the reduction achieved by portfolio 4 (0.030) compared to the baseline is comparable with that of portfolio $13(0.033)$, which provides the minimum exposure among all portfolios compared with an average of 0.0828 . From this figure we can observe that natural assets, given their lower sensitivity with oil risk, can contribute to reducing the oil exposure of the overall portfolio. This observation shows the hedging property associated with natural asset investments. 


\section{Conclusions}

In this work, we have examined the effect of including natural assets (i.e. timber and farmland) in the SAA of an oil-sourced SWF. We model the investment portfolio of the fund following the theoretical approach introduced by Gintschel \& Scherer (2008) and assess its performance based on growth rate, average return, volatility, and portfolio exposure to oil risk during the period Q1 2007- Q1 2016. The allocation strategy and investment universe in our analysis are built taking the portfolio model and mandates from Norway's GPFG as a reference. Historical data on quarterly returns are inputted into our model to represent a global investment universe comprised of equity, fixed-income, real estate, and natural asset instruments. We also conducted a comparison of 16 investment portfolios resulting from different SAA with and without natural assets.

The obtained results indicate that adding timberland and farmland investments in the SAA of an oilbased SWF have a positive effect on the performance of the portfolio. The positive effects are particularly significant when supplanting equity investments with investments in these alternative instruments. Allocating $15 \%$ in timberland and farmland assets can yield a net growth of the fund market value $27 \%$ larger compared to a portfolio composed of traditional assets only, over a nine-year period. In addition, it is found that timberland and farmland assets provide significant reductions in the exposure to commodity risk and improve the return-to-risk characteristic of the portfolio. The benefits of timberland and farmland investments result from the higher average return and lower volatility experienced by these assets in recent years when compared with most equity and real estate markets. This was found to be the case even when adjusted (unsmoothed) returns are considered. Moreover, timberland and farmland tend to exhibit low oil sensitivity that provides them with a hedging property against oil price risk. Our findings suggest that investments in natural assets may be a desirable choice for oil-based SWFs seeking to diversify their investment strategy in the current oil market turmoil. This supports the idea envisioned by some commercial wealth managers that real assets, including natural assets, have the potential to evolve into a mainstream asset class of comparable importance to traditional equity and fixed income assets. Increasing investments in natural assets mean that investors will need to face increasing liquidity risk. Managing this risk, however, can payoff with a 
return premium. In addition, by investing in assets such as timberland and farmland, SWFs could not only benefit from these investments, but they would be redirecting wealth derived from non-renewable natural assets into renewable natural assets. This investment approach implies a circular relationship with natural resources that is in accordance with the Hartwick-Solow ${ }^{1}$ rule of economics. Thus, SWFs could be though as mechanisms that can be adapted to promote sustainable asset allocations and support natural wealth preservation.

One of the main limitations of our study is the constraints found in the data when modelling SWFs. The detailed data required to reconstruct the investment universe and oil inflows are often highly confidential in most SWFs. For this reason, we have used Norway's GPFG as our case study since it is one of the few funds with a high degree of transparency when reporting its activities. Another limitation is found when representing investments in natural assets. This asset class has been limited to investments in timberland and farmland in the US private market. Timberland markets in the US have reached maturity, in consequence, returns have gradually decreased and stabilized in recent years. In search of new opportunities, many institutional investors are currently turning their attention to alternative timber markets in Africa, Asia, and Latin America (UNECE-FAO, 2015). Regarding farmland, despite the US market showing a steady growth in recent years, the higher returns and grow rates have been actually reported in emerging markets such as Romania, Hungary, Poland, Zambia, Mozambique, and Brazil (SavillsResearch, 2014). Timber and farmland markets are opening significant opportunities for SWFs in order to add value to their performance, and therefore, should be promoted as serious alternative investment options. Future work can investigate the effect that investments in emerging timberland and farmland markets may have over oil-founded SWFs portfolio to assess their potential.

\section{Appendix A. Unsmoothing approach}

Fisher et al. (1994) introduce a formal smoothing model to represent the smoothing phenomena expe-

\footnotetext{
${ }^{1}$ In economics literature, the Hartwick-Solow rule refers to compensating the depletion of non-renewable natural capital by reinvesting the economic rent from depletion in renewable capital forms (see Hartwick (1977) and Solow (1974)).
} 
rienced by NCREIF timber and farmland indices. The proposed model relates the observed returns $r_{t}^{*}$ in each time period with the true unobserved returns (i.e. not smoothed) $r_{t}$, using a weighted expression of the form

$$
r_{t}^{*}=w_{0} r_{t}+w(B) r_{t-1},
$$

where $w_{0}$ is a scalar between 0 and 1 , and $w(B)$ is a polynomial function in terms of the lag operator $B$, such that

$$
w(B)=w_{1}+w_{2} B+w_{3} B^{2}+\ldots
$$

From equation (14), the smoothed return can be represented by an autoregressive model as follows

$$
r_{t}^{*}=\psi(B) r_{t-1}^{*}+w_{0} r_{t}
$$

where $\psi(B)$ is a lag polynomial operator specified as $\psi(B)=\psi_{1}+\psi_{4} B^{3}$ to deal with seasonality in the appraisal smoothing. Thus, the smoothing model takes the form

$$
r_{t}^{*}=\psi_{0}+\psi_{1} r_{t-1}^{*}+\psi_{4} r_{t-4}^{*}+w_{0} r_{t} .
$$

Assuming that the mean of the observed returns remains the same as the true returns, and this is given by $E\left(r_{t}\right)=\mu$, we can now rewrite Equation (17) is terms of the true returns as

$$
r_{t}=\mu+\frac{r_{t}^{*}-\psi_{0}-\left(\psi_{1}+\psi_{4} B^{3}\right) r_{t-1}^{*}}{w_{0}}
$$

The coefficients $\psi_{0}, \psi_{1}$, and $\psi_{4}$ can be empirically estimated from the observable data by assuming that the underlying true returns are uncorrelated across time, implying that the term $w_{0} r_{t}$ is white noise. To estimate the value of $w_{0}$ an additional condition must be imposed over the volatility of the true returns (i.e. the volatility of the true returns is $\kappa \%)$. This results in

$$
w_{0}=\frac{\sigma\left(r_{t}^{*}-\psi(B) r_{t-1}^{*}\right)}{\sigma\left(r_{p}\right)}=\frac{\sigma\left(r_{t}^{*}-\psi(B) r_{t-1}^{*}\right)}{\kappa},
$$

At this point, Fisher et al. (1994) assume that the volatility of the true unsmoothed returns of the type represented in the NCREIF indexes equal approximately one-half that of the S\&P500 (i.e. $\kappa=\sigma_{S P} / 2$ ), based on practitioners perception. This notion seems to be supported by Cremers (2013), Malinowski et al. 
(2012) and Davis et al. (2014) on their analysis of timber and farmland returns. Alternatively, Scholtens \& Spierdijk (2010) report that the true volatility of the unsmoothed NCREIF timberland index is 'likely' to be in the range $3-12 \%$.

Alhashel, B. (2015). Sovereign wealth funds: A literature review. Journal of Economics and Business, 78, 1-13.

Ang, A., Goetzmann, W. N., \& Schaefer, S. M. (2009). Evaluation of Active Management of the Norwegian Government Pension Fund Global. Norges Bank Investment Management.

AquilaCapital (2014). Real Assets: The new mainstream. Aquila Capital Investment GmbH.

Azelby, J. K. (2012). The Realization: A new world. A new normal. A tectonic shift. J. P. Morgan Institutional Asset Management.

Balin, B. J. (2008). Sovereing Wealth Funds: A critical analysis. John Hopkins University School of Advanced International Studies.

Beck, R., \& Fidora, M. (2008). The impact of sovereign wealth funds on global financial markets. Intereconomics, 6, 349-358.

Bernstein, S., Lerner, J., \& Schoar, A. (2013). The investment strategy of sovereign wealth funds. Journal of Economic Perspectives, 27, 219-238.

Bertoni, F., \& Lugo, S. (2013). Testing the strategic asset allocation of stabilization sovereign wealth funds. International Finance, 16, 95-119.

Binkley, C. S., Washburn, C., \& Aronow, M. E. (2006). Timberland: The Natural Alternative. Mc Graw Hill Professional.

Bortolotti, B., Fotak, V., \& Loss, G. (2015). The Sky did not fall: Sovereing Wealth Fund Annual Report. Center for Applied Research on International Markets, Banking, Finance and Regulation. Sovereing Investment Lab.

Bortolotti, B., Fotak, V., \& Megginson, W. (2009). Sovereign Wealth Fund Investment Patterns and Performance. Fondazione Eni Enrico Mattei

Bortolotti, B., Fotak, V., \& Pellizzola, L. (2013). SWF Investment in 2013. The Great Reallocation: Sovereign Wealth Fund Annual Report. Fondazione Eni Enrico Mattei.

Boubakri, N., Cosset, J.-C., \& Grira, J. (2016). Sovereign wealth funds target selection: A comparisson with pension funds. Journal of International Financial Markets, Institutions and Money, (pp. 60-76).

Butt, S., Shivdasani, A., Stendevad, C., \& Wyman, A. (2008). Sovereing wealth funds: A growing global force in corporate finance. Journal of Applied Corporate Finance, 20, 73-83.

Caner, M., \& Grennes, T. (2010). Sovereign wealth funds: The norwegian experience. The World Economy, 33, 597-614.

Chambers, D., Dimson, E., \& Ilmanen, A. (2012). The norway model. The Journal of Portfolio Management, 38, 67-81. 
Chhaochharia, V., \& Laeven, L. (2008). Sovereign Wealth Funds: Their investment strategies and performance.

Discussion paper No. DP6959.

Cohen, M., \& McClelland, C. (2015). Angola Sovereign Wealth Fund Seek Mine, Timber investments. Bloomberg.

Courtland, L. W., \& Binkley, C. S. (1993). Do forest assets hedge inflation? Land Economics, 3, 215-224.

Crawford, G., Liew, J. K.-S., \& Marks, A. (2013). Spot commodities as inflation protection. The Journal of Wealth Management, $16,87-111$.

Cremers, K. J. M. (2013). The Performance of Direct Investments in Real Assets: Natural Resources, Infrastructure, and Commercial Real Estate. Deutsche Asset \& Wealth Management. Deutshe Bank.

Davis, H., Minaya, J., \& Hopper, T. (2014). Private real assets: Improving portfolio diversification with uncorrelated market exposure. TIAA-CREF Asset Management.

Dimson, E., Ilmanen, A., Liljeblom, E., \& Sthephansen, O. (2010). Investment Strategy and the GPFG. Norway Ministry of Finance, Oslo.

Dixon, A. D., \& Monk, A. H. B. (2012). Reconciling transparency and long-term investing within sovereign wealth funds. Journal of Sustainable Finance 83 Investment, 3-4, 275-286.

Dyck, I. J. A., \& Morse, A. (2011). Sovereign Wealth Fund Portfolios. MFI Working paper No. 2011-003.

Fisher, J. D., Geltner, D. M., \& Webb, R. B. (1994). Value indices of commercial real estate: A comparisson of index construction methods. Journal of Real Estate Finance and Economics, 9, 137-164.

Fotak, V., Bortolotti, B., Megginson, W., \& Miracky, W. (2008). The financial impact of sovereign wealth fund investments in listed companies. Unpublished working paper, University of Oklahoma and Universita di Torino.

Gieve, J. (2009). Sovereing wealth funds and global imbalances. Revue d economie financiere (Eng. Ed.), 1, 163-177.

Gintschel, A., \& Scherer, B. (2008). Optimal asset allocation for sovereign wealth funds. Journal of Asset Management, 9, $215-238$.

Hardin, W. G., \& Cheng, P. (2002). Farmland investment under conditions of certainty and uncertainty. Journal of Real Estate Finance and Economics, (pp. 81-98).

Hardin, W. G., \& Cheng, P. (2005). Farmland in a mixed asset portfolio: A mean-semivariance approach. Journal of Real Estate Portfolio Management, (pp. 187-195).

Hartwick, J. M. (1977). Intergenerational equity and the investing of rents from exhaustible resources. The American Economic Review, 67, 972-974.

Healey, T., Corriero, T., \& Rozenov, R. (2005). Timber as an institutional investment. The Journal of Alternative Investments, $8,60-74$.

IWG (2008). Sovereign Wealth Funds: Generally Accepted Principles and Practices Santiago Principles. International Working Group of Sovereign Wealth Funds.

Jain, R. (2007). Institutional and individual investor preferences for dividends and share repurchases. Journal of Economics 
Jensen, O. A., \& Seele, P. (2013). An analysis of sovereign wealth and pension funds ethical investment guidelines and their commitment thereto. Journal of Sustainable Finance $\&$ Investment, (pp. 264-282).

Johan, S. A., Knill, A., \& Mauck, N. (2013). Determinants of sovereign wealth fund investment in private equity vs. public equity. Journal of International Business Studies, 44, 155-172.

Kaplan, H. M. (1985). Farmland as portfolio investment. The Journal of Portfolio Management, 11, 73-78.

Kotter, J., \& Lel, U. (2011). Friends of foes? target selection decision of sovereign wealth funds and their consequences. Journal of Financial Economics, 101, 360-381.

Kunzel, P., Lu, Y., Petrova, I., \& Pihlman, J. (2011). Investment Objectives of Sovereign Wealth Funds: A shifting paradigm. IMF working paper.

Lins, D. A., Sherrick, B. J., \& Venigalla, A. (2016). Institutional portfolios: diversification through farmland investments. AREUEA Journal, (pp. 549-571).

Malinowski, J., Smith, N. M., \& Pirone, J. (2012). Weighing the alternatives: How five non-traditional investments stack up. Investment Insights: The Investment Research Journal from Blackrock, 4, 3-30.

McNamara, B. (2015). Institutional Investors are making real assets a portfolio mainstay. Institutional Investors. Available at: http://www.institutionalinvestor.com/.

Mei, B., Clutter, M. L., \& Harris, T. G. (2013). Timberland return drivers and timberland returns and risks: A simulation approach. Southern Journal of Applied Forestry, 37, 18-25.

Miceli, V. (2013). Do sovereign wealth funds herd in equity markets? Quantitative Finance, 10 , $1503-1518$.

Michaud, R. (1998). Efficient Asset Management: A Practical Guide to Stock Portfolio Optimisation and Asset Allocation. Boston, MA: Harvard Business School Press.

MinistryOfFinance (2008). On the management of the Government Pension Fund in 2008. Report No 20 to the Storting (2008-2009). Norway Ministry of Finance.

MinistryOfFinance (2015). The Management of the Government Pension Fund Global in 2014: Report to the Storting (white paper). Norway Ministry of Finance, Oslo.

NorgesBank (2016). Investment Mandate: Government Pension Fund Global. Norges Bank Investment Management.

NPD (2015). Norwegian Petroleum. In cooperation by the Ministry of Petroleum and Energy and The Norwegian Petroleum Directorate. Available at: http://www.norskpetroleum.no/en/.

Papaioannou, M. G., \& Rentsendorj, B. (2015). Sovereign wealth fund asset allocations: Some stylized facts on the norway pension fund global. Procedia Economics and Finance, 29, 195-199.

Riddiough, T. J., Moriarty, M., \& Yeatman, P. J. (2005). Privately versus publicly held asset investment performance. Real Estate Economics, 33, 121-146.

Rubens, J. H., \& Webb, J. R. (1995). Farmland as an inflation hedge. Research Issues in Real Estate: Alternative ideas in 
Real Estate Investment, (pp. 129-142).

SavillsResearch (2014). International Farmland Focus 2014. Savills World Research, International Rural.

Scherer, B. (2002). Boston, ma: Harvard business school press. Financial Analyst Journal, 6, 98-109.

Scherer, B. (2011). Portfolio choice for oil-based sovereign wealth funds. The Journal of Alternative Investments, winter.

Scholtens, B., \& Spierdijk, L. (2010). Does money grow on trees? the diversification properties of us timberland investments. Land Economics, 86, 514-529.

Solow, R. M. (1974). Intergenerational equity and exhaustible resources. Review of Economic Studies, (pp. 29-46).

SovereignWealthFundCenter (2015). Feeling hungry, SWFs ramps up food and agriculture purchases. Available at: http://www.sovereignwealthcenter.com/.

Spiegel, S. (2012). Which financial benchmarks and other incentives work for long-term investing? In P. Bolton, F. Samama, \& J. E. Stiglitz (Eds.), Sovereign Wealth Funds and Long-term Investing (pp. 86-92). Columbia University Press.

Stiglitz, J. E. (2012). Sovereign wealth funds: Distinguishing aspects and opportunities. (pp. 26-31). Sovereign Wealth Funds and Long-term Investing, Columbia University Press.

SWFI (2016). Sovereign Wealth Fund Institute. Available at: http://www.swfinstitute.org/sovereign-wealth-fund-rankings/.

TheEconomist (2014). The Ascent of Real Assets: Gauging Growth and Goals in Institutional Portfolios. BlackRock.

UNECE-FAO (2015). Forest Products: Annual Market Review 2014-2015. United Nations Economic Commission for Europe and Food and Agriculture Organization of the United Nations.

vandenBremer, T., van der Ploeg, F., \& Willis, S. (2016). Managing oil and sovereign wealth. European Economic Review, (pp. 113-131).

Waggle, D., \& Johnson, D. T. (2009). An analysis of the impact of timberland, farmland and commercial real estate in the asset allocation decisions of institutional investors. Review of Financial Economics, 18, 90-96.

Wan, Y., Mei, B., Clutter, M. L., \& Siry, J. P. (2013). Assessing the inflation hedging ability of timberland assets in the united states. Forest Sciences, 59, 93-104.

Xuedong, D. (2014). China will profit the world's appetite. Financial Times.

Zhang, M., Mei, B., Harris, T.-G., Siry, J.-P., \& Baldwin, S.-S. (2011). Can timber hedge against inflation? an analysis of timber prices in the us south. Forest Products Journal, 4, 276-282. 


\section{Tables}

Table 1: Norway's annual petroleum production, petroleum revenues, and capital transferred to the Government Pension Fund Global, 2005-2015. Source: Norwegian Petroleum Directorate (NPD, 2015)

\begin{tabular}{lrrrrrrrrrrrr} 
& \multicolumn{1}{c}{2015} & 2014 & 2013 & 2012 & 2011 & 2010 & 2009 & 2008 & 2007 & 2006 & 2005 \\
\hline Oil production (MMbarrels) & & & & & & & & & & \\
Annual production & 572.2 & 551.9 & 534.3 & 561.1 & 613.4 & 656.6 & 723 & 771.5 & 806.9 & 859.1 & 931.8 \\
\hline Petroleum revenues (US\$ bn) & & & & & & & & & & \\
Taxes & 674.1 & $1,021.2$ & $1,204.2$ & $1,373.8$ & $1,216.3$ & $1,022.3$ & $1,146.4$ & $1,486.8$ & $1,249.4$ & $1,595.5$ & $1,289.6$ \\
Environment Taxes & 31.9 & 27.6 & 19.4 & 13.4 & 12.9 & 14.5 & 15.7 & 23.1 & 25.8 & 25.7 & 26.4 \\
Royalties and Area Fees & 12.4 & 9.0 & 10.0 & 10.5 & 9.0 & 9.1 & 10.1 & 11.3 & 5.3 & 17.9 & 4.5 \\
SDFI Net cash flow & 608.4 & 678 & 742.8 & 894.1 & 754.8 & 683.7 & 661.5 & 953.6 & 744.8 & 947.3 & 770.8 \\
Statoil Dividends & 100.1 & 136.2 & 86.4 & 83.2 & 79.1 & 84 & 107.4 & 104.8 & 93.8 & 95 & 63.8 \\
Total Revenues & $1,426.70$ & $1,871.9$ & $2,062.9$ & $2,375.7$ & $2,072.0$ & $1,813.3$ & $1,941.1$ & $2,579.9$ & $2,119.1$ & $2,681.1$ & $2,154.9$ \\
\hline Capital transferred to GPFG & & & & & & & & & & \\
Inflows (US\$ bn) & - & 882.0 & $1,404.6$ & $1,606.6$ & $1,519.6$ & $1,100.2$ & $1,061.6$ & $2,164.3$ & $1,837.7$ & $1,850.3$ & $1,419.8$ \\
Percentage of revenues (\%) & - & $47.1 \%$ & $68.1 \%$ & $67.7 \%$ & $73.3 \%$ & $60.7 \%$ & $54.7 \%$ & $83.9 \%$ & $86.7 \%$ & $69.0 \%$ & $65.9 \%$ \\
\hline
\end{tabular}


Table 2: Mandates adopted by the Government Pension Fund Global in January 2016. Source: NorgesBank

\begin{tabular}{|c|c|c|}
\hline Mandate & Description & Percentage Range \\
\hline 1 & The fund is to be invested in three asset classes: equities, real estate, and fixed income instruments. & \\
\hline 2 & The fund should be invested aiming to improve the risk-return relationship. & \\
\hline 3 & Exposure to equities of the investment portfolio & $50 \%-70 \%$ \\
\hline 4 & Exposure to Fixed-income instruments & $10 \%-30 \%$ \\
\hline 5 & Exposure to Real Estate of the investment portfolio & $0 \%-5 \%$ \\
\hline \multirow[t]{6}{*}{6} & The real estate portfolio shall be diversified in accordance to: & $0 \%-5 \%$ \\
\hline & US & $30 \%-70 \%$ \\
\hline & UK & $10 \%-40 \%$ \\
\hline & Europe (mainly Germany and France) & $0 \%-20 \%$ \\
\hline & Asia (Japan) & $0 \%-20 \%$ \\
\hline & Other countries & $0 \%-10 \%$ \\
\hline 7 & The fund may not be invested in infrastructure (e.g. roads, railways, harbours, airports, and others) & \\
\hline 8 & Management cost shall not exceed $0.1 \%$ of assets under management & \\
\hline
\end{tabular}


Table 3: Investment universe for the Sovereign Wealth Fund portfolio model

\begin{tabular}{|c|c|c|}
\hline Instrument & Index & Data source \\
\hline \multicolumn{3}{|l|}{ Equity } \\
\hline Basic Materials North America & Dow Jones US Basic Materials Index & Thomson Reuters \\
\hline Basic Materials Europe & STOXX EUR 600 Basic Materials Index & Thomson Reuters \\
\hline Basic Materials Asia & Thomson Reuters Asia/Pacific Basic Materials Index & Thomson Reuters \\
\hline Consumer Goods North America & Dow Jones US Consumer Goods Index & Thomson Reuters \\
\hline Consumer Goods Europe & STOXX EUR 600 Consumer Goods Index & Thomson Reuters \\
\hline Consumer Goods Asia & Dow Jones Asia/Pacific Consumer Goods Index & Thomson Reuters \\
\hline Consumer Services North America & Dow Jones US Consumer Services Index & Thomson Reuters \\
\hline Consumer Services Europe & STOXX EUR Consumer Services Index & Thomson Reuters \\
\hline Consumer Services Asia & Dow Jones Asia/Pacific Consumer Services Index & Thomson Reuters \\
\hline Energy North America & Thomson Reuters US Energy Index & Thomson Reuters \\
\hline Energy Europe & Thomson Reuters EUR Energy Index & Thomson Reuters \\
\hline Energy Asia & Dow Jones Asia/Pacific Oil \& Gas Index & Thomson Reuters \\
\hline Financial North America & Dow Jones US Financial Services Index & Thomson Reuters \\
\hline Financial Europe & STOXX EUR 600 Financial Services Index & Thomson Reuters \\
\hline Financial Asia & Thomson Reuters Asia/Pacific Financial Services Index & Thomson Reuters \\
\hline Health Care North America & Dow Jones US Health Care Index & Thomson Reuters \\
\hline Health Care Europe & STOXX EUR 600 Health Care Index & Thomson Reuters \\
\hline Health Care Asia & MSCI All country Asia/Pacific Health Care Index & Thomson Reuters \\
\hline Industrial North America & Dow Jones US Industrial Index & Thomson Reuters \\
\hline Industrial Europe & STOXX 600 Industrial Index & Thomson Reuters \\
\hline Industrial Asia & Dow Jones Asia/Pacific Industrial Index & Thomson Reuters \\
\hline Technology North America & Dow Jones US Technology Index & Thomson Reuters \\
\hline Technology Europe & STOXX 600 Technology Index & Thomson Reuters \\
\hline Technology Asia & Thomson Reuters Asia/Pacific Technology Index & Thomson Reuters \\
\hline Utility North America & Dow Jones US Utility Index & Thomson Reuters \\
\hline Utility Europe & STOXX 600 Utility Index & Thomson Reuters \\
\hline Utility Asia & Thomson Reuters Asia/Pacific Utilities Index & Thomson Reuters \\
\hline Telecommunications North America & Dow Jones US Telecom Sector Index & Thomson Reuters \\
\hline Telecommunications Europe & STOXX EUR 600 Telecom Index & Thomson Reuters \\
\hline Telecommunications Asia & Thomson Reuters Asia/Pacific Technology Index & Thomson Reuters \\
\hline Equities overall Latin America & MSCI Latin America Price Index & Thomson Reuters \\
\hline \multicolumn{3}{|l|}{ Real Estate } \\
\hline North America & Thomson Reuters US Property Index & Thomson Reuters \\
\hline UK & Thomson Reuters UK Property Index & Thomson Reuters \\
\hline Europe (ex. UK) & Thomson Reuters Europe (ex. UK) Index & Thomson Reuters \\
\hline Asia & Thomson Reuters Asia Property Index & Thomson Reuters \\
\hline \multicolumn{3}{|l|}{ Fixed-income } \\
\hline North America & Barclays Capital US Aggregated Bond Index & Blomberg \\
\hline \multicolumn{3}{|l|}{ Natural Assets } \\
\hline Timberland & NCREIF Timberland Property Index & NCREIF website \\
\hline Farmland & NCREIF Farmland Index & NCREIF website \\
\hline
\end{tabular}


Table 4: Strategic asset allocation of the evaluated portfolios

\begin{tabular}{|c|c|c|c|c|c|}
\hline \multirow[t]{2}{*}{ Portfolio } & \multirow[t]{2}{*}{ Description } & \multicolumn{4}{|c|}{ Strategic Asset Allocation } \\
\hline & & $\mathrm{Eq}$ & Fi & $\operatorname{Re}$ & $\mathrm{Na}$ \\
\hline 1 & Baseline. No natural assets included. & $60.00 \%$ & $35.00 \%$ & $5.00 \%$ & $0.00 \%$ \\
\hline 2 & Replacing $15 \%$ of Eq investments by increasing investments in natural assets. & $51.00 \%$ & $35.00 \%$ & $5.00 \%$ & $9.00 \%$ \\
\hline 3 & Replacing $20 \%$ of Eq investments by increasing investments in natural assets. & $48.00 \%$ & $35.00 \%$ & $5.00 \%$ & $12.00 \%$ \\
\hline 4 & Replacing $25 \%$ of Eq investments by increasing investments in natural assets. & $45.00 \%$ & $35.00 \%$ & $5.00 \%$ & $15.00 \%$ \\
\hline 5 & Replacing $15 \%$ of $\mathrm{Fi}$ investments by increasing investments in natural assets. & $60.00 \%$ & $29.75 \%$ & $5.00 \%$ & $5.25 \%$ \\
\hline 6 & Replacing $20 \%$ of $\mathrm{Fi}$ investments by increasing investments in natural assets. & $60.00 \%$ & $28.00 \%$ & $5.00 \%$ & $7.00 \%$ \\
\hline 7 & Replacing $25 \%$ of $\mathrm{Fi}$ investments by increasing investments in natural assets. & $60.00 \%$ & $26.25 \%$ & $5.00 \%$ & $8.75 \%$ \\
\hline 8 & Replacing $15 \%$ of Re investments by increasing investments in natural assets. & $60.00 \%$ & $35.00 \%$ & $4.25 \%$ & $0.75 \%$ \\
\hline 9 & Replacing $20 \%$ of Re investments by increasing investments in natural assets. & $60.00 \%$ & $35.00 \%$ & $4.00 \%$ & $1.00 \%$ \\
\hline 10 & Replacing $25 \%$ of Re investments by increasing investments in natural assets. & $60.00 \%$ & $35.00 \%$ & $3.75 \%$ & $1.25 \%$ \\
\hline 11 & Replacing $15 \%$ of Eq investments by increasing investments in Fixed-income. & $51.00 \%$ & $44.00 \%$ & $5.00 \%$ & $0.00 \%$ \\
\hline 12 & Replacing $20 \%$ of Eq investments by increasing investments in Fixed-income. & $48.00 \%$ & $47.00 \%$ & $5.00 \%$ & $0.00 \%$ \\
\hline 13 & Replacing $25 \%$ of Eq investments by increasing investments in Fixed-income & $45.00 \%$ & $50.00 \%$ & $5.00 \%$ & $0.00 \%$ \\
\hline 14 & Replacing $15 \%$ of Eq investments by increasing investments in Real Estate. & $51.00 \%$ & $35.00 \%$ & $14.00 \%$ & $0.00 \%$ \\
\hline 15 & Replacing $20 \%$ of Eq investments by increasing investments in Real Estate. & $48.00 \%$ & $35.00 \%$ & $17.00 \%$ & $0.00 \%$ \\
\hline 16 & Replacing $25 \%$ of Eq investments by increasing investments in Real Estate. & $45.00 \%$ & $35.00 \%$ & $20.00 \%$ & $0.00 \%$ \\
\hline
\end{tabular}

Note. $\mathrm{Eq}=$ Equity, $\mathrm{Re}=$ Real estate, $\mathrm{Fi}=$ Fixed-income, $\mathrm{Na}=$ Natural assets 
Table 5: Historical performance of quarterly returns for assets in our investment universe, Q1 2007 - Q1 $\underline{2016}$

\begin{tabular}{|c|c|c|c|c|c|}
\hline Asset & Mean & Std Dev & Sharpe ratio & Oil sensitivity & Correlation with oil \\
\hline N. America Consumer goods & $1.70 \%$ & $7.27 \%$ & 0.209 & 0.11 & 0.34 \\
\hline N. America Consumer services & $2.08 \%$ & $8.43 \%$ & 0.226 & 0.138 & 0.368 \\
\hline N. America Energy & $-0.31 \%$ & $12.69 \%$ & -0.038 & 0.395 & 0.698 \\
\hline N. America Financial & $-0.63 \%$ & $13.39 \%$ & -0.06 & 0.279 & 0.467 \\
\hline N. America Health care & $2.03 \%$ & $7.42 \%$ & 0.25 & 0.126 & 0.38 \\
\hline N. America Industrial & $1.35 \%$ & $11.06 \%$ & 0.106 & 0.222 & 0.451 \\
\hline N. America Technology & $1.82 \%$ & $9.90 \%$ & 0.166 & 0.256 & 0.581 \\
\hline N. America Utilities & $0.82 \%$ & $7.81 \%$ & 0.082 & 0.083 & 0.238 \\
\hline Europe Consumer goods & $1.42 \%$ & $9.59 \%$ & 0.129 & 0.194 & 0.454 \\
\hline Europe Consumer services & $0.37 \%$ & $8.35 \%$ & 0.023 & 0.031 & 0.083 \\
\hline Europe Energy & $-1.49 \%$ & $13.19 \%$ & -0.126 & 0.369 & 0.628 \\
\hline Europe Financial & $-0.86 \%$ & $14.08 \%$ & -0.074 & 0.334 & 0.532 \\
\hline Europe Health care & $1.46 \%$ & $7.07 \%$ & 0.182 & 0.148 & 0.469 \\
\hline Europe Industrial & $0.39 \%$ & $13.13 \%$ & 0.016 & 0.313 & 0.535 \\
\hline Europe Technology & $-0.22 \%$ & $12.43 \%$ & -0.032 & 0.257 & 0.464 \\
\hline Europe Utilities & $-1.71 \%$ & $10.94 \%$ & -0.173 & 0.24 & 0.492 \\
\hline Asia Consumer goods & $0.28 \%$ & $8.74 \%$ & 0.012 & 0.229 & 0.588 \\
\hline Asia Consumer services & $0.47 \%$ & $7.94 \%$ & 0.037 & 0.119 & 0.336 \\
\hline Asia Energy & $-0.51 \%$ & $13.66 \%$ & -0.05 & 0.44 & 0.723 \\
\hline Asia Financial & $-0.54 \%$ & $27.88 \%$ & -0.026 & 0.454 & 0.365 \\
\hline Asia Health care & $0.90 \%$ & $8.21 \%$ & 0.088 & 0.058 & 0.157 \\
\hline Asia Industrial & $-0.08 \%$ & $11.29 \%$ & -0.023 & 0.285 & 0.566 \\
\hline Asia Technology & $0.16 \%$ & $11.19 \%$ & -0.002 & 0.256 & 0.514 \\
\hline Asia Utilities & $-0.53 \%$ & $7.00 \%$ & -0.1 & 0.007 & 0.022 \\
\hline Latinamerica All Equities & $-0.89 \%$ & $16.06 \%$ & -0.067 & 0.502 & 0.702 \\
\hline NorthAmerica (Real Estate) & $1.27 \%$ & $7.66 \%$ & 0.143 & 0.061 & 0.179 \\
\hline UK (Real Estate) & $-1.04 \%$ & $14.09 \%$ & -0.086 & 0.123 & 0.195 \\
\hline Europe (Real Estate) & $-0.25 \%$ & $13.97 \%$ & -0.03 & 0.237 & 0.381 \\
\hline Asia (Real Estate) & $-0.08 \%$ & $9.29 \%$ & -0.028 & 0.178 & 0.429 \\
\hline NorthAmerica (Bonds) & $1.14 \%$ & $1.60 \%$ & 0.603 & -0.02 & -0.286 \\
\hline Timberland (Unsmoothed) & $1.40 \%$ & $3.73 \%$ & 0.329 & 0.01 & 0.058 \\
\hline Farmland (Unsmoothed) & $2.79 \%$ & $3.20 \%$ & 0.816 & 0.004 & 0.029 \\
\hline
\end{tabular}


Table 6: Statistics on the performance of the tested portfolios ranked according to the return to overall risk

\begin{tabular}{|c|c|c|c|c|c|c|c|c|c|}
\hline Portfolio & $\begin{array}{l}\text { Average } \\
\text { Q-return }\end{array}$ & $\begin{array}{l}\text { Financial } \\
\text { Volatility }\end{array}$ & $\begin{array}{l}\text { Financial } \\
\text { Sharpe } \\
\text { ratio }\end{array}$ & $\begin{array}{l}\text { Max. } \\
\text { Drawdown }\end{array}$ & $\begin{array}{l}\text { Oil } \\
\text { correlation }\end{array}$ & Growth & $\begin{array}{l}\text { Oil } \\
\text { exposure }\end{array}$ & $\begin{array}{l}\text { Overall } \\
\text { Risk }\end{array}$ & $\begin{array}{l}\text { Return / } \\
\text { Over. Risk } \\
\text { ratio }\end{array}$ \\
\hline 4 & $0.96 \%$ & $4.33 \%$ & 0.1881 & $28.3 \%$ & 0.547 & $218.4 \%$ & 0.1047 & 0.0846 & 0.114 \\
\hline 3 & $0.90 \%$ & $4.59 \%$ & 0.1649 & $30.5 \%$ & 0.550 & $212.9 \%$ & 0.1114 & 0.0861 & 0.105 \\
\hline 2 & $0.84 \%$ & $4.84 \%$ & 0.1440 & $32.7 \%$ & 0.552 & $207.5 \%$ & 0.1180 & 0.0876 & 0.096 \\
\hline 13 & $0.77 \%$ & $4.31 \%$ & 0.1442 & $29.1 \%$ & 0.527 & $201.0 \%$ & 0.1005 & 0.0840 & 0.091 \\
\hline 12 & $0.75 \%$ & $4.57 \%$ & 0.1316 & $31.1 \%$ & 0.534 & $199.1 \%$ & 0.1080 & 0.0856 & 0.087 \\
\hline 7 & $0.78 \%$ & $5.64 \%$ & 0.1122 & $38.8 \%$ & 0.563 & $201.1 \%$ & 0.1404 & 0.0926 & 0.084 \\
\hline 11 & $0.73 \%$ & $4.83 \%$ & 0.1203 & $33.1 \%$ & 0.541 & $197.3 \%$ & 0.1155 & 0.0872 & 0.083 \\
\hline 6 & $0.76 \%$ & $5.64 \%$ & 0.1083 & $38.9 \%$ & 0.562 & $199.2 \%$ & 0.1399 & 0.0925 & 0.082 \\
\hline 5 & $0.73 \%$ & $5.63 \%$ & 0.1044 & $39.0 \%$ & 0.560 & $197.2 \%$ & 0.1394 & 0.0924 & 0.079 \\
\hline 10 & $0.70 \%$ & $5.52 \%$ & 0.0998 & $38.2 \%$ & 0.557 & $193.6 \%$ & 0.1360 & 0.0917 & 0.076 \\
\hline 9 & $0.69 \%$ & $5.54 \%$ & 0.0984 & $38.4 \%$ & 0.557 & $193.2 \%$ & 0.1364 & 0.0918 & 0.075 \\
\hline 8 & $0.69 \%$ & $5.56 \%$ & 0.0969 & $38.6 \%$ & 0.556 & $192.8 \%$ & 0.1368 & 0.0919 & 0.075 \\
\hline 1 & $0.67 \%$ & $5.62 \%$ & 0.0925 & $39.2 \%$ & 0.555 & $191.5 \%$ & 0.1379 & 0.0922 & 0.072 \\
\hline 14 & $0.62 \%$ & $5.57 \%$ & 0.0848 & $39.9 \%$ & 0.535 & $191.5 \%$ & 0.1318 & 0.0914 & 0.068 \\
\hline 15 & $0.60 \%$ & $5.56 \%$ & 0.0821 & $40.1 \%$ & 0.528 & $191.4 \%$ & 0.1298 & 0.0911 & 0.066 \\
\hline 16 & $0.59 \%$ & $5.56 \%$ & 0.0793 & $40.3 \%$ & 0.520 & $191.4 \%$ & 0.1277 & 0.0909 & 0.065 \\
\hline
\end{tabular}


Figure 1: Returns and market value evolution for the baseline portfolio $(\mathrm{Eq}=60 \%, \mathrm{Fi}=35 \%, \mathrm{Re}=5 \%)$ and Norway's Government Pension Fund Global, Q1 2007 - Q1 2016
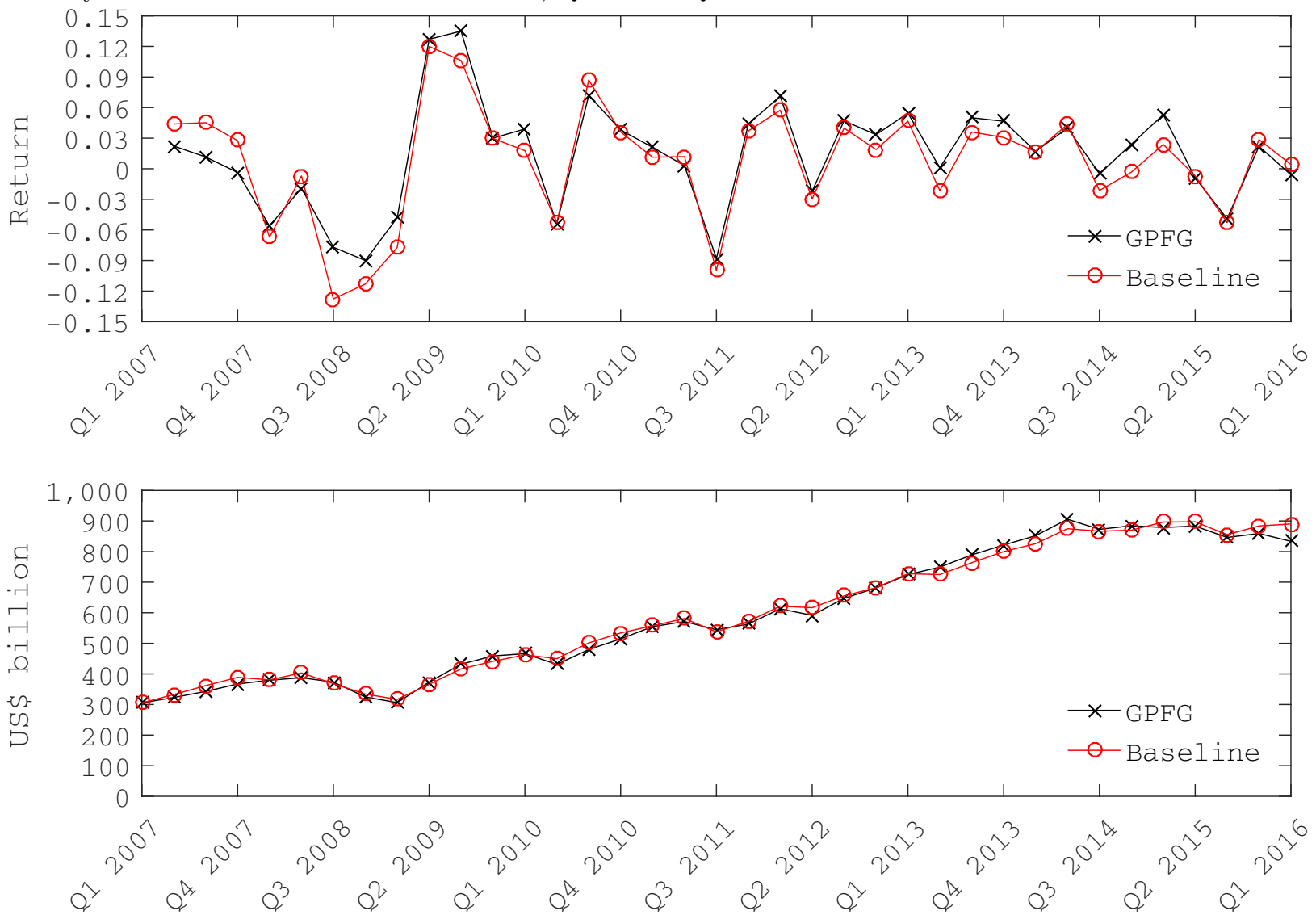
Figure 2: Returns and market value evolution for portfolios 1, 4, 13, and 16, Q1 2007 - Q1 2016
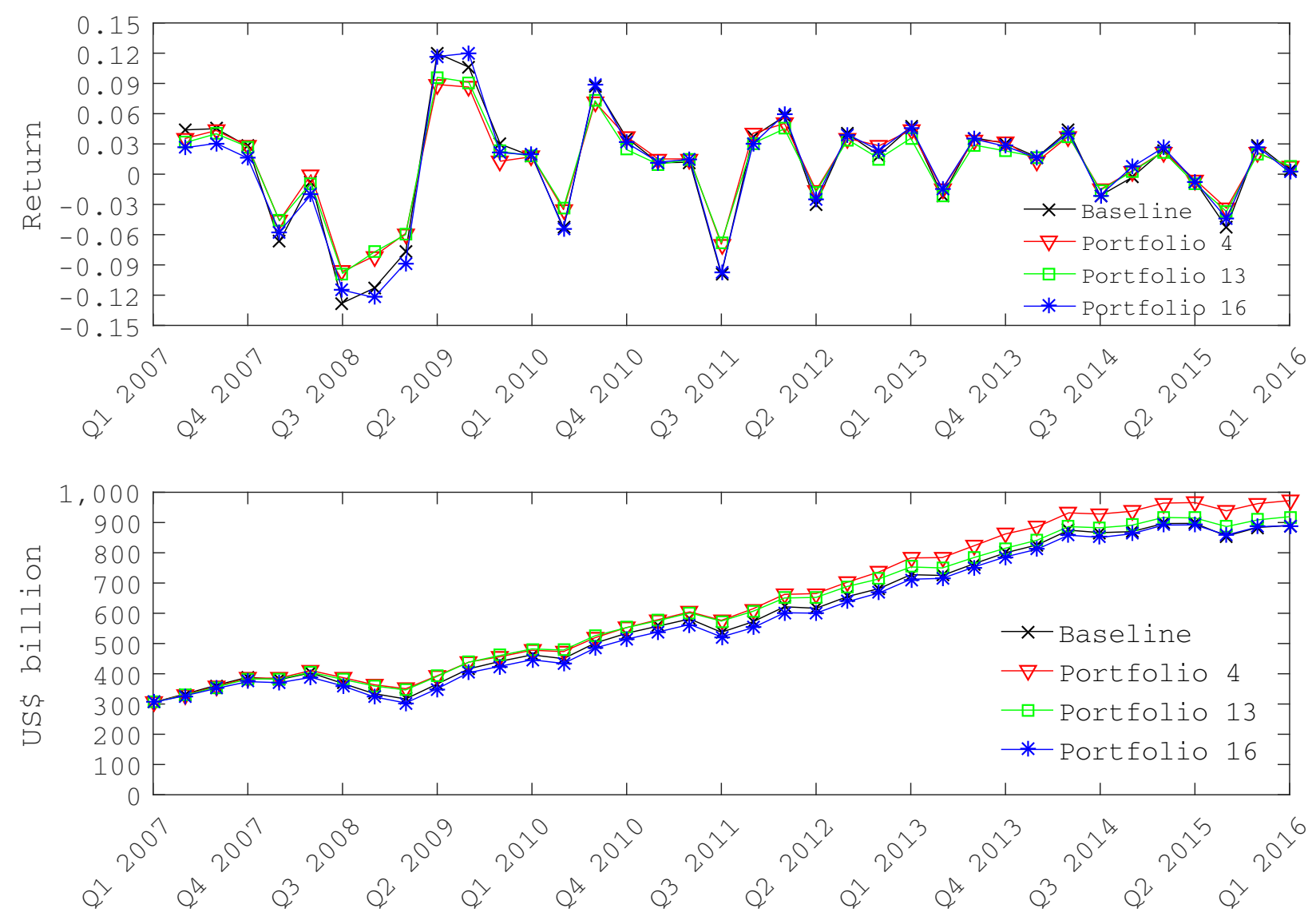
Figure 3: Globally efficient allocations for portfolio $4(\mathrm{Eq}=45 \%, \mathrm{Fi}=35 \%, \mathrm{Re}=5 \%, \mathrm{Na}=15 \%)$

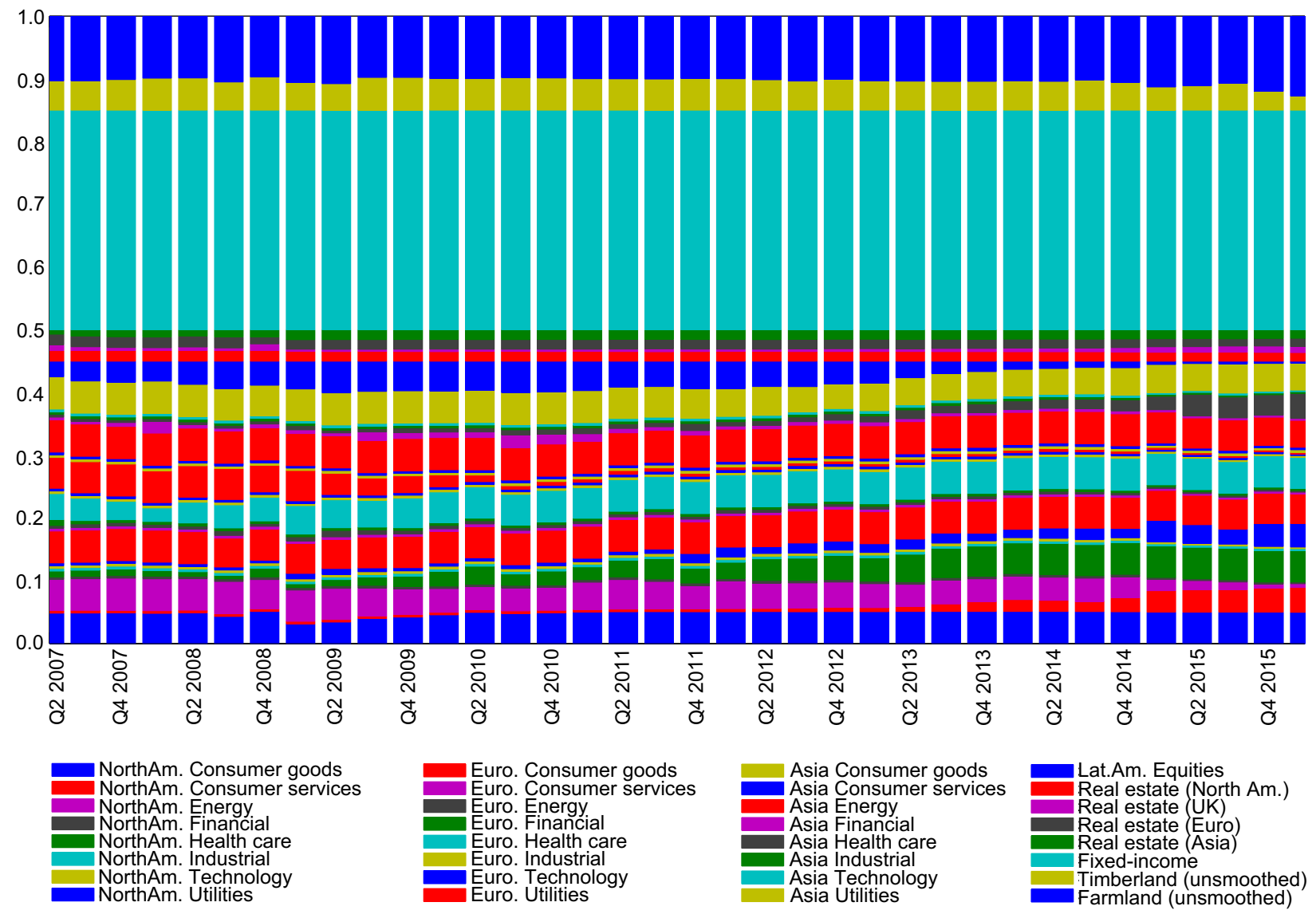


Figure 4: Oil inflows perceived by the Sovereign Wealth Fund

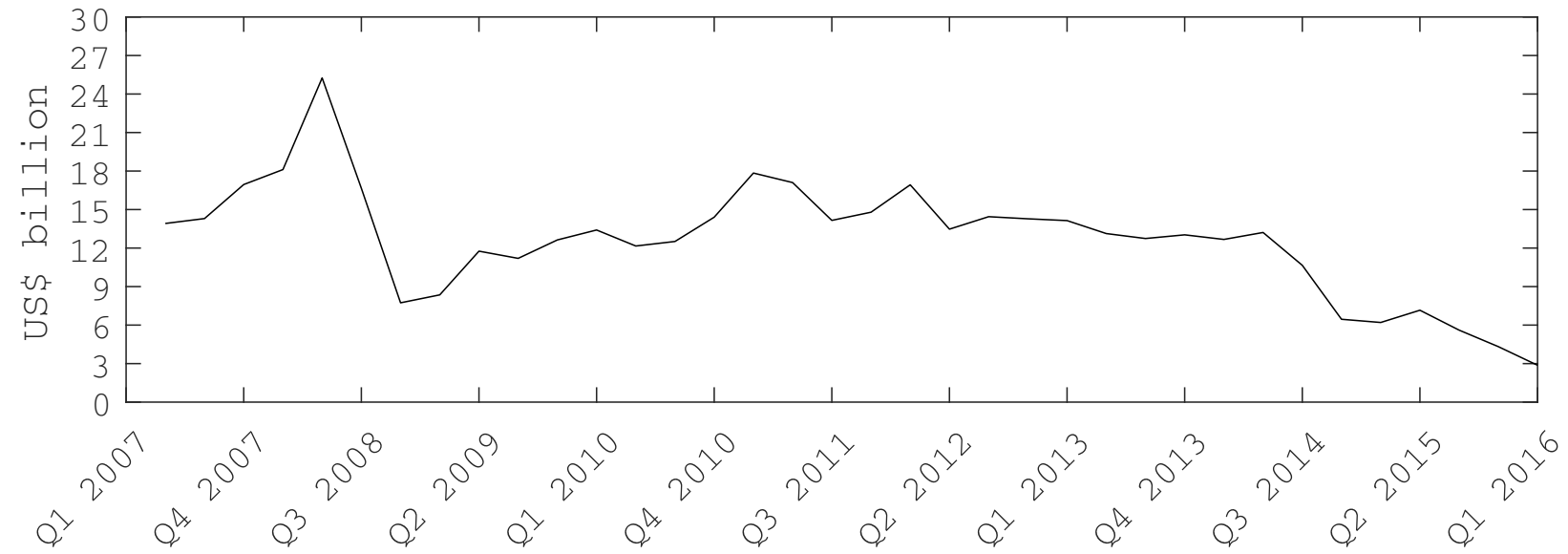


Figure 5: Normalized cumulative capital transferred to the fund and portfolio growth

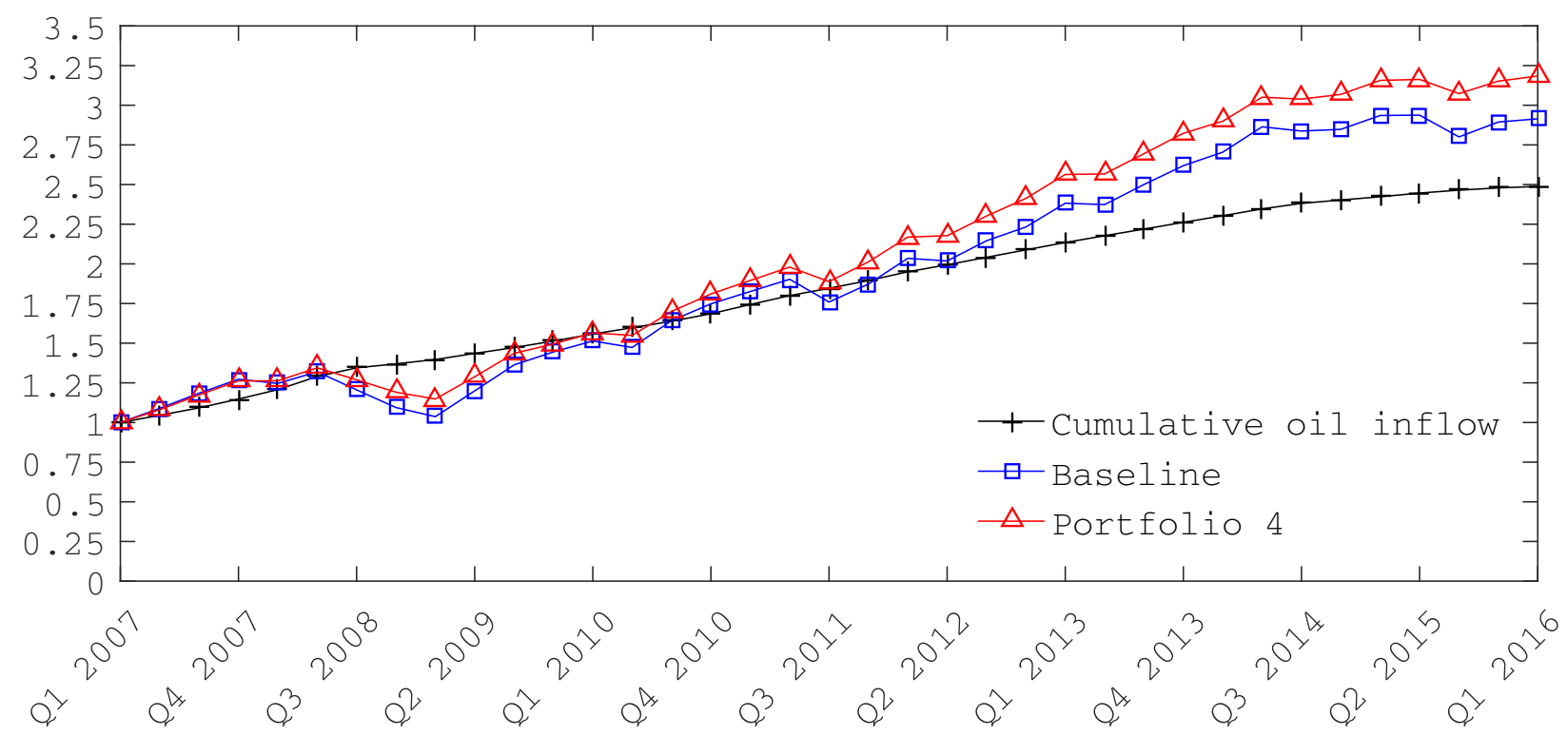


Figure 6: Oil risk exposure for portfolios 1, 4, 13, and 16

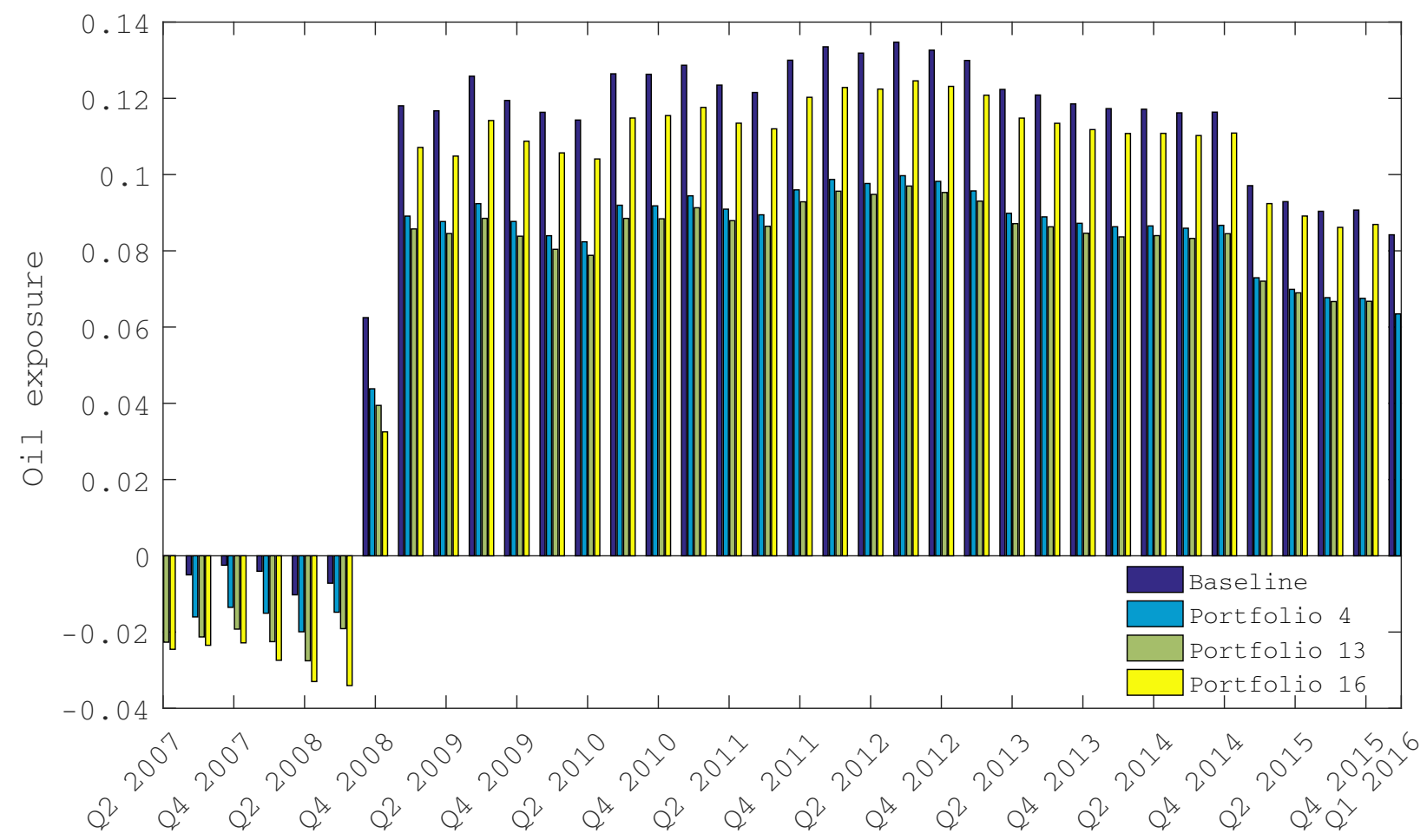

